\title{
The role of stress reactivity in the long-term persistence of adolescent social anxiety symptoms
}

\author{
S.A. Nelemans ${ }^{\mathrm{a}, *}$, W.W. Hale III ${ }^{\mathrm{a}}$, S.J.T. Branje ${ }^{\mathrm{a}}$, P.A.C. van Lier $^{\mathrm{b}}$, H.M. Koot ${ }^{\mathrm{b}}$, \\ W.H.J. Meeus ${ }^{\mathrm{a}, \mathrm{c}}$ \\ ${ }^{a}$ Research Centre Adolescent Development, Utrecht University, P.O. Box 80.140, 3508 TC Utrecht, The Netherlands \\ b Department of Developmental Psychology, VU Amsterdam, Van Der Boechorstraat 1, 1081 BT Amsterdam, The Netherlands

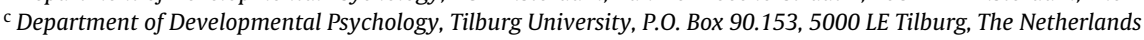

\section{A R T I C L E I N F O}

\section{Article history:}

Received 25 March 2016

Received in revised form 30 January 2017

Accepted 2 March 2017

Available online 6 March 2017

\section{Keywords:}

Social anxiety disorder (SAD) symptoms

Adolescence

Stress reactivity

Developmental processes

Public speaking task

\begin{abstract}
A B S T R A C T
Social Anxiety Disorder (SAD) symptoms demonstrate a marked persistence over time, but little is known empirically about short-term processes that may account for this long-term persistence. In this study, we examined how self-reported and physiological stress reactivity were associated with persistence of SAD symptoms from early to late adolescence. A community sample of 327 adolescents ( $56 \%$ boys, $M_{\mathrm{age}}=13.01$ at $T_{1}$ ) reported their SAD symptoms for 6 successive years and participated in a public speaking task, during which self-reported (i.e., perceived nervousness and heart rate) and physiological (i.e., cortisol and heart rate) measures of stress were taken. Overall, our results point to a developmental process in which adolescents with a developmental history of higher SAD symptoms show both heightened perceived stress reactivity and heart rate reactivity, which, in turn, predict higher SAD symptoms into late adolescence.
\end{abstract}

(c) 2017 Elsevier B.V. All rights reserved.

\section{Introduction}

Social Anxiety Disorder (SAD) symptoms involve a marked and persistent fear of one or more social or performance situations in which the person is exposed to unfamiliar people or to possible scrutiny by others (American Psychiatric Association, 2013). Adolescence, the period of life between approximately 12 and 18 years of age, is a critical phase for the development of SAD symptoms. During adolescence a key feature of SAD symptoms, fear of negative social evaluation, increases (Weems \& Costa, 2005; Westenberg, Drewes, Goedhart, Siebelink, \& Treffers, 2004), and social stress is experienced more frequently and intensely than in other age periods. Moreover, SAD symptoms are among the most prevalent

\footnotetext{
is Data of the RADAR study were used. RADAR has been financially supported by main grants from the Netherlands Organisation for Scientific Research (GB-MAGW 480-03-005, GB-MAGW 480-08-006), Stichting Achmea Slachtoffer en Samenleving (SASS), the Netherlands Organisation for Scientific Research to the Consortium Individual Development (CID; 024.001.003), and various other grants from the Netherlands Organisation for Scientific Research, the VU University Amsterdam, and Utrecht University. The authors would like to thank all schools and families for their participation.

* Corresponding author.

E-mail address: s.a.nelemans@uu.nl (S.A. Nelemans).
}

manifestations of psychopathology during adolescence, with a 12month prevalence of $8.2 \%$ for adolescent SAD (Kessler et al., 2012) and a lifetime prevalence increasing from $7.7 \%$ in early adolescence to $10.1 \%$ in late adolescence in the United States (Merikangas et al., 2010). Additionally, adolescent SAD symptoms show a marked persistence over time (Kessler et al., 2012) and the clinical manifestation of SAD typically has its onset in early to mid-adolescence (Kessler et al., 2005). Yet, fairly little is known about developmental processes that may account for this strong persistence in adolescent SAD symptoms. In the present study, we used a novel approach in examining whether stress reactivity as a short-term process may play a role in the long-term persistence of adolescent SAD symptoms from early to late adolescence.

\subsection{Theoretical model on persistence of SAD symptoms}

Most studies on the persistence of SAD symptoms have been conducted with adult participants, based on the well-known theoretical model of Clark and Wells (1995). A key assumption in this model (and later extensions, e.g., Rapee \& Heimberg, 1997) is that both psychological distress and physiological hyper-reactivity to feared social situations play a crucial role in SAD symptom persistence. Specifically, in anticipation of feared situations indi- 
viduals with high levels of SAD symptoms are assumed to engage in a variety of negatively biased cognitive processes. Because of these processes, they experience strong increases in both psychological distress and physiological activity. Several interlinked mechanisms then reinforce their negative cognitive biases as well as their psychological distress and physiological activity in the short-term (Clark \& Wells, 1995; Rapee \& Heimberg, 1997). At the same time, individuals with high levels of SAD symptoms interpret their heightened distress and physiological activity as a sign of (impending or actual) failure to meet desired standard of social performance or to convey an acceptable impression to others. Thereby, they are more likely to interpret the situation as posing a threat, which reinforces their fear of such situations in the future. This negative spiral is theorized to play a critical role in SAD symptom persistence in the long-term (Clark \& Wells, 1995).

The theoretical model of Clark and Wells (1995) assumes some sort of congruence in levels of psychological distress and physiological activity in response to a stressful situation. However, there generally appears to be only modest concordance, at best, among measures of distress and physiological activity (Hollenstein \& Lanteigne, 2014; Mauss, Levenson, McCarter, Wilhelm, \& Gross, 2005). These responses may thus occur relatively independent of each other, even in reaction to a social stressor (e.g., Lanteigne, Flynn, Eastabrook, \& Hollenstein, 2014). Individuals with high levels of SAD symptoms may not necessarily show concordance in their patterns of psychological and physiological responding in socially stressful situations (Mauss, Wilhelm, \& Gross, 2004).

Furthermore, during adolescence major cognitive developmental changes occur (Steinberg, 2005). Additionally, important developmental changes occur in the physiological systems that underlie emotional sensitivity, arousal, and downregulation (i.e., the autonomic nervous system and the hypothalamus-pituitary-adrenal system; Spear, 2009). Therefore, adolescence is a critical period to study psychological and physiological processes that play a prominent role in the theoretical model of SAD symptom persistence.

\subsection{Empirical studies on SAD symptoms and stress reactivity}

Empirical studies examining associations between SAD symptoms and stress reactivity typically use public speaking paradigms, because these paradigms are known to elicit social-evaluative threat by placing individuals in an often feared social-performance situation in front of an audience (Dickerson \& Kemeny, 2004; Westenberg et al., 2009). Using these paradigms, stress reactivity has typically been studied by relying on markers of two major human stress-response systems: the relatively fast responding autonomic nervous system (ANS) and the relatively slow responding hypothalamus-pituitary-adrenal system (HPA-axis). Heart rate is the most studied physiological marker of ANS activity and cortisol levels are the most studied physiological marker of HPA-axis activity. Their counterparts subjectively perceived heart rate and nervousness/stress are the most studied psychological markers of ANS activity and HPA-axis activity, respectively.

Consistent with the theoretical model of SAD symptom persistence (Clark \& Wells, 1995), the few studies that have specifically focused on adolescent SAD symptoms and perceived stress reactivity generally report greater increases in perceived stress and heart rate from baseline to the stress-task (e.g., Krämer et al., 2012; Schmitz, Krämer, Tuschen-Caffier, Heinrichs, \& Blechert, 2011; Schmitz, Tuschen-Caffier, Wilhelm, \& Blechert, 2013; for a recent systematic review, see Siess, Blechert, \& Schmitz, 2014). However, results are mixed regarding associations between adolescent SAD symptoms and physiological measures of stress reactivity (see Siess et al., 2014). Some studies suggest that (pre-)adolescent SAD symptoms are associated with heightened heart rate during a public speaking paradigm (Krämer et al., 2012) or heightened cortisol reactivity from baseline to the stress-task (Van West, Claes, Sulon, \& Deboutte, 2008). In contrast, other studies do not find heightened heart rate reactivity (e.g., Anderson \& Hope, 2009; Schmitz et al., 2011, 2013) or heightened cortisol reactivity (e.g., Krämer et al., 2012; Martel et al., 1999) from baseline to the stress-task. Hence, there does not appear to be consistent support for the theoretical idea that high levels of SAD symptoms are associated with strong increases in physiological activity in a social-performance situation (Clark \& Wells, 1995).

Given the large variability between studies in design, research samples, assessments of SAD as well as stress reactivity, and time-intervals, it is not possible to attribute different findings to any single cause. One important confounding factor might be whether the study included assessments during an anticipatory phase (e.g, Krämer et al., 2012) or not (e.g., Anderson \& Hope, 2009). Theoretically, strong increases in both psychological distress and physiological activity may occur even before actual exposure to a feared situation (Clark \& Wells, 1995; Rapee \& Heimberg, 1997). Some indeed suggest that socially anxious individuals may show stronger stress responses in anticipation of a speech-task rather than during the speech-task itself (Coles \& Heimberg, 2000). Yet, little is known about adolescent SAD symptoms and potential anticipation effects, since anticipation effects have not been consistently studied in adolescent populations, and the few existing findings are inconsistent.

Clearly, more work on associations between adolescent SAD symptoms and physiological stress reactivity during feared socialperformance situations is needed. Moreover, to our knowledge, no previous study has explicitly tested whether perceived and physiological stress reactivity predict later levels of adolescent SAD symptoms. Therefore, it is still empirically unknown whether perceived and physiological stress reactivity may be associated with the persistence of adolescent SAD symptoms over (longer periods of) time.

\subsection{The present study}

The goal of the present study was to examine whether stress reactivity, as a short-term process, may account for long-term persistence in SAD symptoms from early to late adolescence. Adolescence is a particularly significant period to study how both perceived and physiological stress-related processes may be involved in the development and persistence of SAD symptoms over time, because this is a crucial period for the development of SAD symptoms and characterized by major cognitive changes and changes in functioning of the ANS and HPA-axis as well (Spear, 2009; Steinberg, 2005). For this purpose, we used a novel longitudinal design.

First, we examined individual differences in developmental trajectories of SAD symptoms over 5 successive years, from early to late adolescence, in a relatively large community sample of adolescents. Developmental psychopathology (Cicchetti \& Rogosch, 2002) and developmental models specific to anxiety (e.g., Weems, 2008) emphasize the importance of taking into account individuals' developmental history for a more comprehensive understanding of individual psychosocial functioning. Furthermore, focusing on adolescents' developmental history of SAD symptoms allowed us to identify those adolescents most at risk for persistent high SAD symptoms, for whom it would be most salient to understand what short-term processes may play a role in this persistence over longer periods of time.

Second, we examined how these individual differences in developmental histories of SAD symptoms were associated with perceived and physiological stress reactivity during a public speaking task (PST) at a later moment in time, as well as how perceived and physiological stress reactivity were in turn associated with 
later SAD symptoms. Based on theoretical models on SAD symptom persistence (Clark \& Wells, 1995; Rapee \& Heimberg, 1997) and in line with some empirical findings (Siess et al., 2014), we hypothesized that adolescents with a developmental history of higher SAD symptoms would show both heightened perceived and physiological reactivity in anticipation of and/or during the PST and that this heightened stress reactivity would be associated with later adolescent SAD symptoms. Statistically, such associations would suggest a significant indirect or mediational effect. Furthermore, the model by Clark and Wells (1995) also suggests that the ending of a socially stressful situation may not necessarily bring an immediate end to particularly the psychological distress of individuals with higher levels of SAD symptoms (i.e., post-event processing). Therefore, we hypothesized that adolescents with a developmental history of higher SAD symptoms might show attenuated decreases in perceived stress levels after the PST, which could be associated with later adolescent SAD symptoms.

This study is, to our knowledge, the first to explicitly test whether both perceived and physiological stress reactivity may be associated with persistence of adolescent SAD symptoms over longer periods of time. By combining long-term longitudinal survey data on adolescent SAD symptom development with short-term assessments of psychological distress and physiological activity in an experimental setting, this study has a unique potential to uncover potential psychological and physiological mechanisms underlying adolescent SAD symptom development. Also, the present study extends existing research on associations between SAD symptoms and stress reactivity by including both self-reported and physiological measures of the ANS and the HPA-axis (i.e., stress/nervousness and heart rate) during different phases of a PST in a large longitudinal community sample of adolescents. It is important to distinguish between different phases (e.g., anticipation, stress-task, and recovery) not only because the ANS and HPA-axis are assumed to show differential activation in response to stress, but also because anticipation anxiety as well as delayed recovery from a stressful situation (i.e., persisting negative thoughts and distress) play an important role in theoretical models on the persistence of SAD (Clark \& Wells, 1995). Furthermore, research in adolescent community samples is needed for more insight into general processes that may contribute to the development and persistence of SAD symptoms. It will aid our understanding of developmental processes that occur before SAD symptoms have reached problematic or clinical levels. Findings from clinical samples may have limited generalizability to community samples as a result of a potential referral bias and findings in adults cannot simply be extrapolated to adolescents, because of strong cognitive, emotional, social, and physiological developmental changes during adolescence.

\section{Method}

\subsection{Participants}

The sample consisted of 327 ethnic Dutch adolescents (57\% boys; $M_{\text {age }}=13.01, S D_{\text {age }}=0.44$ at the start of the study; $5.9 \%$ from low SES families based on parents' job level) participating in the ongoing longitudinal Research on Adolescent Development And Relationships (RADAR Young) project. All the participating adolescents identified themselves as ethnic Dutch and attended the first year of secondary school at the start of the study. From the total longitudinal RADAR Young sample of 497 participants (57\% boys; $M_{\text {age }}=13.03, S D_{\text {age }}=0.46$ at the start of the study; $10.8 \%$ from low SES families), 327 participants (66\%) agreed to participate in the laboratory session including the PST. Because of our study aims, we only included data in our study from participants who partic- ipated in the PST. Our study sample $(n=327)$ did not significantly differ from those not participating in the PST $(n=170)$ in terms of sex, $\chi^{2}(1)=0.12, p=0.73$, age, $F(1,495)=2.90, p=0.09$, and SAD symptoms at the start of the study, $F(1,487)=1.23, p=0.27$, but participants who participated in the PST were more likely to come from medium to high SES families, $\chi^{2}(1)=22.32, p<0.001$, Cramer's $V=0.22$.

\subsection{Procedure}

Participants were recruited from randomly selected primary schools in the western and central regions of the Netherlands. From these schools, Dutch adolescents in the final grade from intact twoparent families were randomly selected for participation. Before the start of the study, all participants and their parents received a complete description of the study and $70 \%$ of the selected families provided active written informed consent $(N=497)$. Data collection started in the new academic year, when all participants attended the first year of secondary school. The final sample consisted of only one adolescent (with some exceptions including two adolescents) from every secondary school.

Adolescents completed annual self-report questionnaires during a home visit for 6 successive years (from approximately ages 13-18), and were invited to participate in a laboratory session in between the fifth and sixth annual assessment (between ages 17 and 18). Both parents and adolescents were again asked for active consent. Depending on where the participant resided, the laboratory session took place in one of two collaborating universities (i.e., the Faculty of Social Sciences, Utrecht University, the Netherlands, and the Faculty of Psychology and Education, VU University Amsterdam, the Netherlands). The laboratory session was conducted by a trained experimenter and took place in a specially equipped room that was kept at room temperature $\left(M=20.43^{\circ} \mathrm{C}, S D=1.00\right)$. The PST was scheduled between 3 and 4 PM, to account for diurnal changes in cortisol levels.

We used the protocol of the Leiden PST, in which participants have the opportunity to prepare for their speech (instead of an impromptu speech) and perform the speech-task in front of a life-size projection of a pre-recorded (instead of a live) audience consisting of age-matched peers and a teacher (participants were told beforehand that the audience was pre-recorded; for a complete description of the PST, see Westenberg et al., 2009). The audience was recorded while entering an empty classroom, taking their seats at the desks, and looking into the camera to give the impression of attending to the presenter. The PST contained four major phases (see Table 1): baseline (watching a nature documentary; 15 min. sitting, $5 \mathrm{~min}$. standing), anticipation ( $9 \mathrm{~min}$.), the speech-task ( $5 \mathrm{~min}$.), and recovery (watching the remainder of the nature documentary; $5 \mathrm{~min}$. standing, $15 \mathrm{~min}$. sitting). Participants watched a documentary before and after the speech-task to allow for adequate assessment of baseline and recovery physiological activity levels, cortisol levels in particular. In the anticipation phase, participants were informed about the upcoming speech-task and detailed standardized instructions were given to participants highlighting the social-evaluative nature of the speech-task ("instruction"), followed by $5 \mathrm{~min}$. to prepare for the speech ("preparation"), and subsequently the start of a life-size projection of the pre-recorded audience entering, sitting down, and attending to the presenter ("audience entering").

Two small adaptations to the original Leiden PST protocol were made. First, whereas an interview was conducted with participants after the speech-task in the original Leiden PST, we only used Visual Analogue Scales (VAS; Davey, Barratt, Butow, \& Deeks, 2007) to assess participants' subjectively perceived distress and a short questionnaire instead of an interview to assess participants' other experiences of the speech-task and potential covariates. This 
Table 1

Global Timeline of the Public Speaking Task (PST) in the Present Study.

\begin{tabular}{|c|c|c|}
\hline Time (in minutes) & Phases/activities & Assessments \\
\hline 0 & $\begin{array}{l}\text { Early baseline } \\
\text { watch nature documentary sitting }\end{array}$ & Start continuous heart rate monitoring ${ }^{\mathrm{a}}$ \\
\hline 15 & watch nature documentary standing & \\
\hline 20 & End baseline & Perceived nervousness \& Perceived heart rate at end baseline \\
\hline 21 & $\begin{array}{l}\text { Anticipation } \\
\text { instruction }\end{array}$ & \\
\hline 24 & preparation & \\
\hline 29 & audience entering (on screen) & \\
\hline 30 & Speech-task & \\
\hline 35 & End speech-task & $\begin{array}{l}\text { Perceived nervousness \& Perceived heart rate during speech-task and } \\
\text { at short-term recovery + Cortisol representing end baseline }\end{array}$ \\
\hline 35 & Recovery & \\
\hline 40 & watch nature documentary standing & \\
\hline 45 & watch nature documentary sitting & Cortisol representing preparation \\
\hline 50 & watch nature documentary sitting & Cortisol representing speech-task \\
\hline 55 & watch nature documentary sitting & Cortisol representing short-term recovery \\
\hline 60 & watch nature documentary sitting & \\
\hline 65 & End of procedure & $\begin{array}{l}\text { Perceived nervousness \& Perceived heart rate at long-term } \\
\text { recovery + Cortisol representing long-term recovery } \\
\text { End continuous heart rate monitoring }\end{array}$ \\
\hline
\end{tabular}

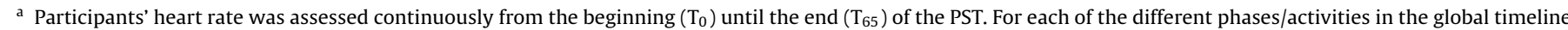
above, we calculated participants' average heart rate in beats per minute.

adaptation was made so that the participant was alone in the room during the entire PST session and was not affected by any social interaction with the experimenter. Second, a 5-min. recovery standing phase was included directly after the speech-task to control for potential effects of body position or postural change. This entire study was approved by the board of the local research institute and by the Medical Ethical Committees of the Utrecht Medical Centre and the VU Medical Centre, the Netherlands.

\subsection{Measures}

\subsubsection{SAD symptoms}

We used the SAD subscale of the Dutch Screen for Child Anxiety Related Emotional Disorders (SCARED; Birmaher et al., 1997; Hale, Raaijmakers, Muris, \& Meeus, 2005) to assess adolescent SAD symptoms. Participants rated their SAD symptoms on a 3-point scale, ranging from 1 (almost never) to 3 (often). A sample item includes "It is hard for me to talk with people I don't know well". Reliability of the SAD subscale was good over all six waves $(\alpha=0.74-0.85$ ). This SAD subscale has demonstrated good psychometric properties, including good concurrent, discriminant, and predictive validity (e.g., Hale et al., 2005; Muris, Dreessen, Bögels, Weckx, \& Van Melick, 2004; Muris, Merckelbach, Ollendick, King, \& Bogie, 2002; Ogliari et al., 2012).

\subsubsection{Perceived nervousness}

VAS scales were used to assess participants' perceived nervousness at four points during the PST; after baseline, during the speech (which was measured retrospectively directly after the speech task), directly after the speech (which was measured after participants' ratings of their nervousness and heart rate during the speech task), and after the recovery phase. Participants rated their nervousness on a $10-\mathrm{cm}$. line. All lines were printed on separate pages and participants were instructed to turn pages after each VAS assessment. The point marked by the participants on each of the lines was measured in centimeters to represent their perceived nervousness.

\subsubsection{Cortisol}

Saliva samples were collected at different points during the PST to obtain participants' cortisol levels. Participants were instructed to collect their saliva through a small straw into a polypropylene tube after baseline (t20), after the speech (t35), 10 min. after the speech (t45), followed by four samples with time intervals of $5 \mathrm{~min}$. (t50-65). Due to a delay in peak levels of free cortisol, these samples each reflect neuroendocrine activity approximately 20 min. earlier (Dickerson \& Kemeny, 2004; Westenberg et al., 2009). For this reason, and for reasons of consistency with the other assessments of psychological distress and physiological activity, we only used the cortisol measurements representing baseline standing/end baseline ( $\mathrm{t} 35$ ), preparation ( $\mathrm{t} 45$ ), the speech-task $(\mathrm{t} 50)$, short-term recovery ( $\mathrm{t} 55)$, and long-term recovery ( $\mathrm{t} 65)$ in our analyses (see Table 1). After the session, the tubes with saliva were stored uncentrifuged at $-20^{\circ} \mathrm{C}$. Cortisol was analyzed using electrochemiluminescence immunoassay (ECLIA; E170 Roche, Switzerland) at the laboratory of the Leiden University Medical Center (the Netherlands). The lower detection limit was $0.5 \mathrm{nmol} / \mathrm{L}$, with mean intra-assay and inter-assay coefficients of variation of $3.4 \%$ and $12.2 \%$. Outliers greater than 3.29 SD above or below the mean were removed from the analyses ( $n=26$ across all five cortisol samples).

\subsubsection{Perceived heart rate}

VAS scales were used to assess participants' perceived heart rate at four points during the PST; after baseline, during the speech (which was measured retrospectively directly after the speech task), directly after the speech (which was measured after participants' ratings of their nervousness and heart rate during the speech task), and after the recovery phase. Participants rated how fast their heart was beating on a $10-\mathrm{cm}$. line. All lines were printed on separate pages and participants were instructed to turn pages after each VAS assessment. The point marked by the participants on each of the lines was measured in centimeters to represent their perceived heart rate.

\subsubsection{Heart rate}

An ambulatory measuring system (VU Ambulatory Monitoring System device; http://www.vu-ams.nl) was used to continuously measure participants' heart rate during all phases of the PST. Measurement of participants' heart rate began at the start of the baseline phase of the PST (t0) and ended at the end of the recovery phase of the PST (t65; see Table 1 ). Data were automatically scored with special software (AMS Suite Software). Heart rate (in average beats per minute) was calculated for every phase of the PST. Outliers greater than $3.29 S D$ above or below the mean were 
removed from the analyses ( $n=7$ across all seven phases during which participants' average heart rate was calculated).

\subsubsection{Possible confounders}

In addition to including sex as possible confounder of stress reactivity during the PST in all statistical models, we considered time of awakening, Body Mass Index (BMI), contraceptive use (yes/no), and use of alcohol/cigarettes/cannabis/sedatives in the last $24 \mathrm{~h}$. (yes/no) before the PST as possible confounders of cortisol reactivity specifically, as these confounders have been previously linked to cortisol levels (Adam \& Kumari, 2009; Kudielka \& Wüst, 2010).

\subsection{Statistical analyses}

Our statistical analysis strategy consisted of a two-step approach, where we first examined individual differences in adolescent SAD symptoms and subsequently examined how these individual differences in adolescent SAD symptoms were associated with stress reactivity and later SAD symptoms. Specifically, we first examined individual differences in adolescents' developmental trajectories of SAD symptoms over the five years before they participated in the PST, from approximately age 13-17. For this purpose, we used Growth Mixture Modeling (GMM; Nagin, 2005) in Mplus 7.31 (Muthén \& Muthén, 2012). To determine the number of subgroups of adolescents with different developmental trajectories of SAD symptoms over the 5 -year period before the PST we relied on four criteria. First, identifying an additional subgroup should result in an improvement of model fit. A decrease in the Sample Size Adjusted Bayesian Information Criterion (SSA BIC) and a significant adjusted Lo, Mendell, and Rubin likelihood ratio test (adj. LMR-LRT) are indicative of this. Second, entropy-a measure of classification quality-should be acceptable. Entropy values range from zero to one, where values closer to one indicate better classification. Third, we evaluated the interpretability of the different subgroups. If a subgroup was found to be a slight variation of a subgroup already present in a lower class solution, we chose the most parsimonious model. Fourth and finally, every group had to cover at least $5 \%$ of the sample for meaningful interpretation.

After determining the number of subgroups with different developmental trajectories of SAD symptoms over five successive years, posterior group membership probabilities for each individual for the identified classes were used in further analysis. Hereby, we adequately dealt with classification uncertainty and inaccuracy. The alternative approach of using each individual's most likely class membership, that is, their classification to the class with the highest posterior group membership probability, ignores the fact that classification of individuals is not perfect (which would be suggested by an entropy value of exactly one).

Second, we examined the role of perceived and physiological stress reactivity during different phases of a PST in the persistence of individual differences in adolescents' developmental history of SAD symptoms $\left(\mathrm{T}_{1}-\mathrm{T}_{5}\right.$; from approximately ages $\left.13-17\right)$ and 1 -year later SAD symptoms $\left(\mathrm{T}_{6}\right.$; approximately age 18$)$. Stress reactivity is typically calculated by taking the absolute or percentual difference between successive assessments of stress. However, such a procedure does not take measurement error into account and may thereby result in biased estimates. Therefore, we constructed structural equation models in Mplus 7.31 (Muthén \& Muthén, 2012) with latent difference scores as more accurate and pure reflections of stress reactivity. Specifically, rather than first calculating a series of difference scores for each individual over the different phases of the PST to use in our statistical analyses, differences between subsequent assessments of stress were captured in a series of latent scores (McArdle, 2009) for each individual that were estimated in Mplus as part of our statistical models. These latent difference

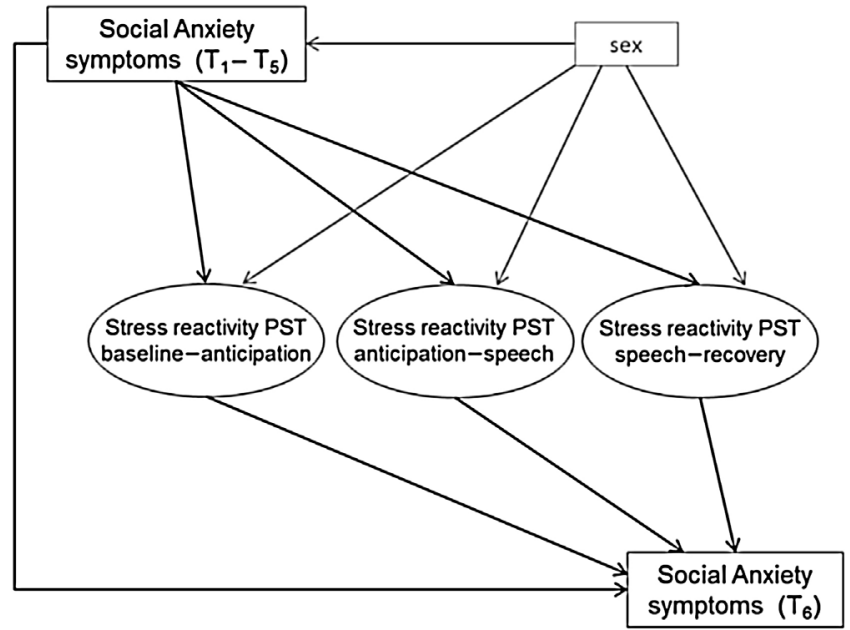

Fig. 1. Global overview of our statistical models, estimated separately for each measure of psychological distress (i.e., perceived nervousness and perceived heart rate) and physiological activity (i.e., cortisol levels and heart rate).

scores were defined as "the part of the score of $Y_{t+1}$ that is not identical to $Y_{t}$ " and thereby represent the change from $Y$ measured at one moment in time $(t)$ to another moment in time $(t+1)$, rather than specifying any form of subtraction as would be the case for absolute or percentual difference scores (for more details on latent difference score modeling, we would like to refer readers to McArdle, 2009).

Phases before and after the speech-task were modeled separately, due to problems in estimating the initial increases and subsequent decreases in stress levels during the PST in one model. This resulted in a total of 8 models; for each of the four markers of stress reactivity (i.e., perceived nervousness, perceived heart rate, cortisol levels, and heart rate) we ran one model including all assessments from baseline to the stress-task and one model including all assessments from the stress-task to the recovery phase (i.e., 2 models $\times 4$ measures of stress). Since only few studies have included an anticipatory phase and not all included assessments of stress reactivity, we made optimal use of the Leiden PST design and modeled the "instruction", "preparation", and "audience entering" as distinct parts of the anticipatory phase. Thereby, we aimed to gain a more in-depth understanding of associations between adolescent SAD symptoms and stress reactivity in anticipation of a socially stressful situation. See Table 2 for an overview of all successive assessments of stress during different phases of the PST for the different measures. Sex was included as a potential covariate of stress reactivity in all models (see Fig. 1 for a global overview of our statistical models).

In the latent difference score models, we examined predictive longitudinal associations between adolescents' developmental history of SAD symptoms $\left(\mathrm{T}_{1}-\mathrm{T}_{5}\right)$, the different measures of perceived and physiological stress reactivity during the different phases of the PST, and later SAD symptoms $\left(\mathrm{T}_{6}\right)$. We thus examined longitudinal mediation models, where we accounted for persistence in SAD symptoms by including the predictive longitudinal association between adolescents' developmental history of SAD symptoms $\left(\mathrm{T}_{1}-\mathrm{T}_{5}\right)$ and later SAD symptoms $\left(\mathrm{T}_{6}\right)$. All estimations of the longitudinal indirect effects were based on the Mplus estimation of indirect effects, including bias-corrected confidence intervals (MacKinnon, Lockwood, \& Williams, 2004) with 10,000 bootstrap draws. Model fit was assessed with the Comparative Fit Index (CFI), the Root Mean Squared Error of Approximation (RMSEA) and its 90\% confidence interval (CI), and the Standardized Root Mean Square Residual (SRMR), using conventional standards (see Hu \& Bentler, 1999; Kline, 2005). Only few data were missing; missing values ranged 
Table 2

Descriptive Statistics of all Study Variables.

\begin{tabular}{|c|c|c|c|c|c|c|c|c|}
\hline & \multirow{3}{*}{$\begin{array}{l}\text { Annual } \\
M(S D)\end{array}$} & \multicolumn{7}{|c|}{ Public Speaking Task } \\
\hline & & \multirow{2}{*}{$\begin{array}{l}\text { Baseline } \\
\text { End } M(S D)\end{array}$} & \multicolumn{3}{|l|}{ Anticipation } & \multirow{2}{*}{$\begin{array}{l}\text { Speech-task } \\
M(S D)\end{array}$} & \multicolumn{2}{|l|}{ Recovery } \\
\hline & & & $\begin{array}{l}\text { Instruction } M \\
(S D)\end{array}$ & $\begin{array}{l}\text { Preparation } M \\
(S D)\end{array}$ & $\begin{array}{l}\text { Audience } \\
\text { entering } M(S D)\end{array}$ & & $\begin{array}{l}\text { Short- term } M \\
(S D)\end{array}$ & $\begin{array}{l}\text { Long-term } M \\
(S D)\end{array}$ \\
\hline SAD symptoms $T_{1}$ & $\begin{array}{l}1.63 \\
(0.47)\end{array}$ & & & & & & & \\
\hline SAD symptoms $T_{2}$ & $\begin{array}{l}1.44 \\
(0.47)\end{array}$ & & & & & & & \\
\hline SAD symptoms $T_{3}$ & $\begin{array}{l}1.47 \\
(0.51)\end{array}$ & & & & & & & \\
\hline SAD symptoms $\mathrm{T}_{4}$ & $\begin{array}{l}1.44 \\
(0.50)\end{array}$ & & & & & & & \\
\hline SAD symptoms $T_{5}$ & $\begin{array}{l}1.42 \\
(0.49)\end{array}$ & & & & & & & \\
\hline SAD symptoms $T_{6}$ & $\begin{array}{l}1.43 \\
(0.50)\end{array}$ & & & & & & & \\
\hline \multicolumn{2}{|c|}{ Perceived nervousness } & $\begin{array}{l}0.99 \\
(1.39)\end{array}$ & & & & $\begin{array}{l}4.96 \\
(2.69)\end{array}$ & $\begin{array}{l}3.11 \\
(2.44)\end{array}$ & $\begin{array}{l}0.50 \\
(0.98)\end{array}$ \\
\hline \multicolumn{2}{|c|}{ Perceived heart rate } & $\begin{array}{l}1.39 \\
(1.54)\end{array}$ & & & & $\begin{array}{l}4.76 \\
(2.54)\end{array}$ & $\begin{array}{l}3.41 \\
(2.26)\end{array}$ & $\begin{array}{l}0.84 \\
(1.29)\end{array}$ \\
\hline \multicolumn{2}{|l|}{ Cortisol } & $\begin{array}{l}5.83 \\
(2.82)\end{array}$ & & $\begin{array}{l}6.03 \\
(3.13)\end{array}$ & & $\begin{array}{l}5.49 \\
(3.26)\end{array}$ & $\begin{array}{l}4.95 \\
(2.76)\end{array}$ & $\begin{array}{l}4.32 \\
(2.39)\end{array}$ \\
\hline \multicolumn{2}{|l|}{ Heart rate } & $\begin{array}{l}78.78 \\
(10.38)\end{array}$ & $\begin{array}{l}83.91 \\
(12.53)\end{array}$ & $\begin{array}{l}84.80 \\
(12.23)\end{array}$ & $\begin{array}{l}86.29 \\
(14.36)\end{array}$ & $\begin{array}{l}92.16 \\
(14.93)\end{array}$ & $\begin{array}{l}77.19 \\
(10.79)\end{array}$ & $\begin{array}{l}66.94 \\
(8.89)\end{array}$ \\
\hline
\end{tabular}

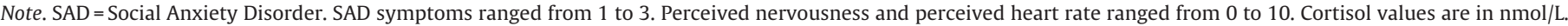
Heart rate are in average beats per minute.

from $1.2 \%$ to $5.8 \%$ for SAD symptoms across all six waves, from $0.6 \%$ to $0.9 \%$ for perceived nervousness and perceived heart rate, from $3.1 \%$ to $4.6 \%$ for cortisol, and from $6.1 \%$ to $7.6 \%$ for heart rate across all statistically modelled phases of the PST. Missing data were handled with Full Information Maximum Likelihood (Muthén \& Muthén, 2012).

\section{Results}

\subsection{Descriptive statistics SAD symptoms}

The means and standard deviations of all six annual assessments of SAD symptoms are shown in Table 2. Overall, mean levels of SAD symptoms were relatively low, as may be expected in a community sample, and appeared to be somewhat lower in comparison with a different Dutch longitudinal community sample (Nelemans et al., 2014). Using cut-off scores (i.e., mean levels of SAD >2; Birmaher et al., 1997), 7.5\%-12.7\% of adolescents showed clinically significant levels of SAD symptoms at some point in the six successive years. Successive assessments of adolescent SAD symptoms showed high rank-order stability over six years, with Pearson's correlations ranging between 0.53 and 0.73 .

\subsection{Descriptive statistics PST}

An overview of the means and standard deviations of all assessments during the PST are shown in Table 2. These means show that nearly all perceived and physiological measures of stress increased from baseline to the anticipation and/or speech-task phase of the PST, followed by a sharp decrease from the speech-task phase into the recovery phases (with the exception of cortisol, which slightly increased from baseline to anticipation of the speech-task, but decreased after this). This suggests that the PST generally seemed to elicit stress-responses in the total sample and that these stressresponses diminished after the speech-delivery phase when the adolescents were no longer exposed to the social-evaluative stressor.
Rank-order stability between successive assessments of stress was moderate to high for all measures taken during the PST. Specifically, Pearson's correlations ranged between 0.34 and 0.78 for perceived nervousness, between 0.28 and 0.78 for perceived heart rate, between 0.76 and 0.89 for cortisol, and between 0.77 and 0.95 for heart rate, respectively. Correlations between successive assessments of our physiological measures were particularly high when assessments were very close together (i.e., anticipation phase for heart rate and recovery phase for cortisol). An overview of the correlations between SAD symptoms and all assessments during the PST is shown in Table 3. Overall, SAD symptoms over six years appeared to be weakly to moderately positively associated with perceived nervousness, perceived heart rate, and heart rate during several phases of the PST $(r=-0.01-0.31)$, whereas SAD symptoms appeared to be unrelated to cortisol $(r=-0.12-0.07)$.

\subsection{Heterogeneity in developmental trajectories of SAD symptoms}

Based on the four criteria described earlier, results from GMM suggested that individual differences in SAD symptoms over the five successive years, from early to late adolescence, could be best described by two different subgroups of adolescents, $\triangle$ SSA $\mathrm{BIC}=-44.66$, entropy $=0.77, p=0.01$. Although a three subgroup solution resulted in a slightly better model fit and entropy, one distinguished subgroup of adolescents consisted of less than 5\% of the sample and was thereby too small for meaningful interpretation. The majority of adolescents $(80 \%)$ were classified into a subgroup showing relatively low SAD symptoms in early adolescence $\quad\left(M_{\text {intercept }}=1.46, M_{\text {linear slope }}=-0.16, M_{\text {quadratic slope }}=0.03\right)$, which showed a slight decline from early to late adolescence. A smaller subgroup of adolescents (20\%) showed higher SAD symptoms in early adolescence $\left(M_{\text {intercept }}=2.08, M_{\text {linear slope }}=0.07, M_{\text {quadratic slope }}=-0.03\right)$, which remained relatively stable throughout adolescence with a slight decline towards the end of adolescence. Based on these characteristics, we labelled the first larger subgroup "Low SAD" and the 
Table 3

Correlations Between all Study Variables.

\begin{tabular}{|c|c|c|c|c|c|c|c|c|c|c|}
\hline & (1) & $(2)$ & (3) & (4) & $(5)$ & (6) & $(7)$ & $(8)$ & (9) & $(10)$ \\
\hline \multicolumn{11}{|l|}{ Perceived nervousness } \\
\hline (1) End baseline & - & & & & & & & & & \\
\hline (2) Speech task. & $0.37^{* *}$ & - & & & & & & & & \\
\hline (3) Short-term recovery & $0.34^{* *}$ & $0.78^{* *}$ & - & & & & & & & \\
\hline (4) Long-term recovery & $0.56^{* *}$ & $0.28^{* *}$ & $0.34^{* *}$ & - & & & & & & \\
\hline \multicolumn{11}{|l|}{ Perceived heart rate } \\
\hline (5) End baseline & $0.59^{* *}$ & $0.27^{* *}$ & $0.27^{* *}$ & $0.43^{* *}$ & - & & & & & \\
\hline (6) Speech task & $0.37^{* *}$ & $0.82^{* *}$ & $0.68^{* *}$ & $0.28^{* *}$ & $0.39^{* *}$ & - & & & & \\
\hline (7) Short-term recovery & $0.37^{* *}$ & $0.66^{* *}$ & $0.70^{* *}$ & $0.29^{* *}$ & $0.41^{* *}$ & $0.78^{* *}$ & - & & & \\
\hline (8) Long-term recovery & $0.34^{* *}$ & $0.23^{* *}$ & $0.22^{* *}$ & $0.56^{* *}$ & $0.53^{* *}$ & $0.29^{* *}$ & $0.28^{* *}$ & - & & \\
\hline \multicolumn{11}{|l|}{ Cortisol } \\
\hline (9) End baseline & 0.05 & -0.00 & 0.02 & 0.04 & 0.10 & 0.03 & 0.04 & 0.01 & - & \\
\hline (10) Preparation & 0.05 & 0.09 & 0.05 & 0.01 & 0.06 & 0.07 & 0.01 & 0.03 & $0.75^{* *}$ & - \\
\hline (11) Speech task & 0.00 & 0.09 & 0.08 & -0.02 & 0.01 & 0.11 & 0.05 & -0.03 & $0.63^{* *}$ & $0.82^{* *}$ \\
\hline (12) Short-term recovery & -0.01 & 0.05 & 0.05 & -0.05 & 0.01 & 0.06 & -0.01 & -0.01 & $0.62^{* *}$ & $0.79^{* *}$ \\
\hline (13) Long-term recovery & -0.02 & 0.01 & 0.01 & -0.03 & 0.02 & 0.02 & -0.00 & -0.03 & $0.63^{* *}$ & $0.73^{* *}$ \\
\hline \multicolumn{11}{|l|}{ Heart rate } \\
\hline (14) End baseline & 0.01 & 0.10 & 0.02 & -0.07 & 0.03 & 0.09 & 0.04 & -0.07 & 0.10 & 0.11 \\
\hline (15) Instruction & 0.09 & $0.22^{* *}$ & $0.13^{*}$ & -0.04 & 0.06 & $0.25^{* *}$ & $0.17^{* *}$ & -0.03 & $0.15^{*}$ & $0.22^{* *}$ \\
\hline (16) Preparation & 0.11 & $0.18^{* *}$ & 0.10 & -0.05 & 0.01 & $0.21^{* *}$ & $0.15^{* *}$ & -0.08 & 0.08 & $0.16^{* *}$ \\
\hline (17) Audience entering & $0.14^{*}$ & $0.23^{* *}$ & $0.17^{* *}$ & 0.00 & 0.05 & $0.26^{* *}$ & $0.18^{* *}$ & -0.08 & 0.11 & $0.17^{* *}$ \\
\hline (18) Speech task & 0.06 & $0.18^{* *}$ & $0.13^{*}$ & -0.06 & 0.02 & $0.22^{* *}$ & $0.18^{* *}$ & -0.07 & 0.09 & $0.15^{*}$ \\
\hline (19) Short-term recovery & 0.04 & $0.13^{*}$ & 0.08 & -0.04 & 0.01 & $0.13^{*}$ & 0.10 & -0.08 & 0.07 & $0.12^{*}$ \\
\hline (20) Long-term recovery & 0.06 & 0.11 & 0.05 & 0.03 & 0.05 & 0.11 & 0.06 & -0.03 & 0.07 & $0.12^{*}$ \\
\hline SAD symptoms $T_{1}$ & $0.17^{* *}$ & $0.18^{* *}$ & 0.11 & 0.10 & 0.09 & $0.16^{* *}$ & 0.09 & 0.07 & -0.07 & -0.08 \\
\hline SAD symptoms $T_{2}$ & $0.15^{* *}$ & $0.23^{* *}$ & $0.22^{* *}$ & 0.07 & 0.08 & $0.16^{* *}$ & 0.10 & 0.05 & 0.06 & 0.04 \\
\hline SAD symptoms $T_{3}$ & 0.09 & $0.22^{* *}$ & $0.19^{* *}$ & 0.08 & 0.11 & $0.20^{* *}$ & $0.13^{*}$ & 0.01 & 0.05 & 0.02 \\
\hline SAD symptoms $T_{4}$ & 0.11 & $0.17^{* *}$ & $0.19^{* *}$ & $0.11^{*}$ & 0.06 & 0.09 & 0.08 & 0.04 & -0.01 & 0.02 \\
\hline SAD symptoms $T_{5}$ & $0.23^{* *}$ & $0.28^{* *}$ & $0.31^{* *}$ & $0.12^{*}$ & 0.11 & $0.22^{* *}$ & $0.20^{* *}$ & 0.09 & 0.05 & 0.04 \\
\hline \multirow[t]{2}{*}{ SAD symptoms $\mathrm{T}_{6}$} & $0.24^{* *}$ & $0.25^{* *}$ & $0.26^{* *}$ & $0.18^{* *}$ & $0.12^{*}$ & $0.22^{* *}$ & $0.20^{* *}$ & $0.12^{*}$ & -0.04 & -0.05 \\
\hline & $(11)$ & $(12)$ & $(13)$ & $(14)$ & $(15)$ & $(16)$ & $(17)$ & $(18)$ & $(19)$ & $(20)$ \\
\hline \multicolumn{11}{|l|}{$\begin{array}{l}\text { Perceived nervousness } \\
\text { (1) End baseline } \\
\text { (2) Speech task } \\
\text { (3) Short-term recovery } \\
\text { (4) Long-term recovery }\end{array}$} \\
\hline \multicolumn{11}{|l|}{$\begin{array}{l}\text { Perceived heart rate } \\
\text { (5) End baseline } \\
\text { (6) Speech task } \\
\text { (7) Short-term recovery } \\
\text { (8) Long-term recovery }\end{array}$} \\
\hline \multicolumn{11}{|l|}{$\begin{array}{l}\text { Cortisol } \\
\text { (9) End baseline } \\
\text { (10) Preparation }\end{array}$} \\
\hline (11) Speech task & - & & & & & & & & & \\
\hline (12) Short-term recovery & $0.89^{* *}$ & - & & & & & & & & \\
\hline (13) Long-term recovery & $0.75^{* *}$ & $0.81^{* *}$ & - & & & & & & & \\
\hline \multicolumn{11}{|l|}{ Heart rate } \\
\hline (14) End baseline & $0.12^{*}$ & $0.12^{*}$ & 0.09 & - & & & & & & \\
\hline (15) Instruction & $0.23^{* *}$ & $0.18^{* *}$ & $0.17^{* *}$ & $0.78^{* *}$ & - & & & & & \\
\hline (16) Preparation & $0.17^{* *}$ & $0.13^{*}$ & $0.13^{*}$ & $0.80^{* *}$ & $0.95^{* *}$ & - & & & & \\
\hline (17) Audience entering & $0.21^{* *}$ & $0.16^{* *}$ & $0.16^{* *}$ & $0.70^{* *}$ & $0.90^{* *}$ & $0.90^{* *}$ & - & & & \\
\hline (18) Speech task & $0.19^{* *}$ & $0.16^{* *}$ & $0.14^{*}$ & $0.70^{* *}$ & $0.87^{* *}$ & $0.89^{* *}$ & $0.88^{* *}$ & - & & \\
\hline (19) Short-term recovery & 0.11 & 0.10 & 0.09 & $0.92^{* *}$ & $0.82^{* *}$ & $0.83^{* *}$ & $0.77^{* *}$ & $0.77^{* *}$ & - & \\
\hline (20) Long-term recovery & 0.11 & 0.10 & 0.10 & $0.81^{* *}$ & $0.74^{* *}$ & $0.76^{* *}$ & $0.70^{* *}$ & $0.68^{* *}$ & $0.86^{* *}$ & - \\
\hline SAD symptoms $T_{1}$ & -0.03 & -0.02 & -0.00 & 0.06 & $0.16^{* *}$ & $0.17^{* *}$ & $0.22^{* *}$ & $0.15^{* *}$ & 0.10 & 0.09 \\
\hline SAD symptoms $T_{2}$ & 0.03 & 0.06 & 0.07 & 0.02 & 0.07 & 0.06 & 0.11 & 0.10 & 0.01 & -0.01 \\
\hline SAD symptoms $T_{3}$ & 0.03 & 0.06 & 0.07 & 0.09 & $0.20^{* *}$ & $0.16^{* *}$ & $0.19^{* *}$ & $0.17^{* *}$ & 0.09 & 0.10 \\
\hline SAD symptoms $T_{4}$ & 0.00 & -0.01 & -0.01 & 0.09 & $0.19^{* *}$ & $0.14^{*}$ & $0.22^{* *}$ & $0.16^{* *}$ & 0.11 & 0.09 \\
\hline SAD symptoms $T_{5}$ & 0.05 & 0.02 & -0.02 & 0.08 & $0.24^{* *}$ & $0.16^{* *}$ & $0.22^{* *}$ & $0.18^{* *}$ & $0.12^{*}$ & 0.07 \\
\hline SAD symptoms $\mathrm{T}_{6}$ & -0.01 & -0.01 & 0.03 & 0.10 & $0.20^{* *}$ & $0.18^{* *}$ & $0.22^{* *}$ & $0.15^{*}$ & $0.14^{*}$ & $0.13^{*}$ \\
\hline
\end{tabular}

Note. ${ }^{*} p<0.05 ;{ }^{* *} p<0.01$.

second smaller subgroup "Higher SAD" (see Fig. 2 for a graphical representation of the two subgroups).

In the Low SAD subgroup, adolescents' posterior probabilities for those classified in this subgroup ranged from 0.50 to $1.00(M=0.95$, $S D=0.10$ ) whereas posterior probabilities for those classified in the
Higher SAD subgroup ranged from 0.00 to $0.50(M=0.05, S D=0.10)$. In the Higher SAD subgroup, adolescents' posterior probabilities for those classified in this subgroup ranged from 0.53 to $1.00(M=0.86$, $S D=0.15$ ) whereas posterior probabilities for those classified in the Low SAD subgroup ranged from 0.00 to $0.48(M=0.14, S D=0.15)$. 


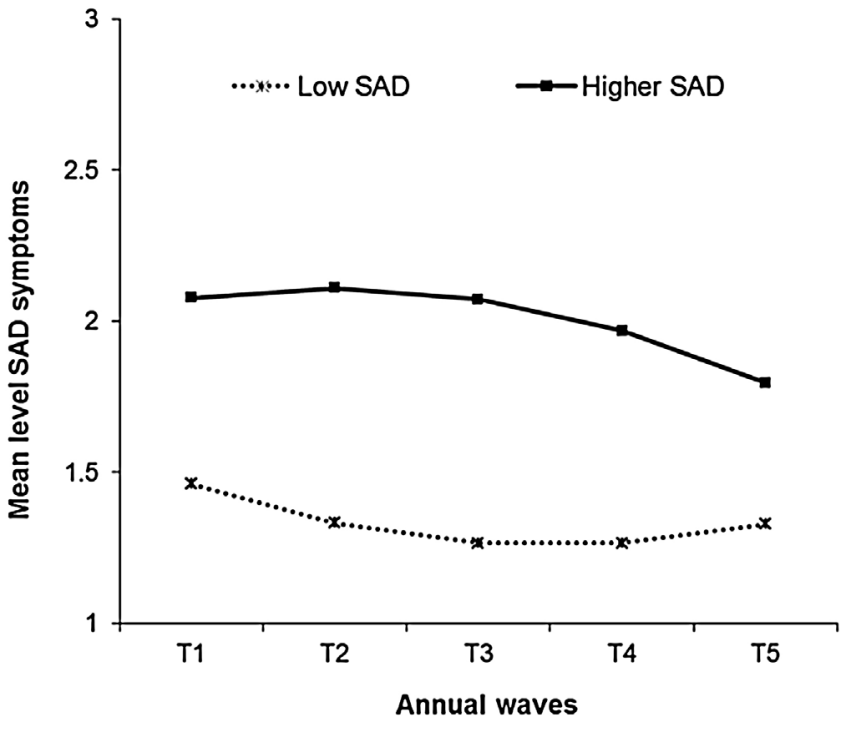

Fig. 2. Graphical representation of the two SAD symptom trajectories in the final GMM model. In the Low SAD trajectory, both the linear and the quadratic slope factors were statistically significant $(p<0.001)$. In the Higher SAD trajectory, neither the linear nor the quadratic slope factor was statistically significant ( $p=0.39$ and $p=0.053$, respectively). Mean levels of SAD symptoms ranged from 1 to 3 .

Overall, boys showed higher posterior probabilities for the Low SAD subgroup $(M=0.87, S D=0.28)$ than girls $(M=0.69, S D=0.40)$, whereas girls showed higher posterior probabilities for the Higher SAD subgroup $(M=0.31, S D=0.40)$ than boys $(M=0.13, S D=0.28)$, $F(1,325)=22.88, p<0.001, \eta^{2}=0.07$. Therefore, sex was included as a covariate of the posterior probabilities in the main analyses.

\subsection{Developmental trajectory of SAD symptoms and perceived nervousness reactivity}

See Table 4 for an overview of all results regarding associations between adolescents' developmental history of SAD symptoms $\left(T_{1}-T_{5}\right)$, perceived nervousness reactivity during different phases of the PST, and later SAD symptoms $\left(\mathrm{T}_{6}\right)$.

\subsubsection{SAD symptoms and perceived anticipatory nervousness}

(from baseline to the speech-task)

The SEM model showed good fit, $\chi^{2}(1)=5.23, \mathrm{CFI}=0.98$, RMSEA $[90 \% \mathrm{CI}]=0.11[0.04,0.22], \mathrm{SRMR}=0.04$. Consistent with theoretical suggestions and past research, results suggested that adolescents

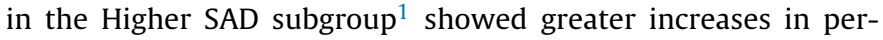
ceived nervousness from baseline to the speech-task, $\beta=0.62$. These greater increases in perceived nervousness from baseline to the speech-task were also significantly associated with higher SAD symptoms at $\mathrm{T}_{6}, \beta=0.25$.

\subsubsection{SAD symptoms and perceived nervousness recovery (from} the speech-task to recovery)

The SEM model showed good fit, $\chi^{2}(3)=5.77, \mathrm{CFI}=0.99$, RMSEA $[90 \% \mathrm{CI}]=0.05[.00,0.12] \mathrm{SRMR}=0.03$. Results suggested that adolescents in the Higher SAD subgroup showed a slower decrease (i.e., stronger persistence) in perceived nervousness from the

\footnotetext{
${ }^{1}$ From this point onwards in the Results section of this manuscript, we will use the class labels "Low SAD" and "Higher SAD" to refer to individuals' posterior probabilities. Specifically, by adolescents in the Low SAD subgroup we refer to adolescents' with higher probabilities of having a developmental history characterized by low SAD symptoms, and by adolescents in the Higher SAD subgroup we refer to adolescents' with higher probabilities of having a developmental history characterized by higher SAD symptoms.
}

speech-task to short-term recovery, $\beta=0.18$. Furthermore, stronger decreases in perceived nervousness from short-term recovery to long-term recovery were significantly associated with higher SAD symptoms at $\mathrm{T}_{6}, \beta=-0.19$.

\subsubsection{Indirect effects}

A significant indirect effect was found for adolescents in the Higher SAD subgroup $\left(\mathrm{T}_{1}-\mathrm{T}_{5}\right)$ via increased perceived nervousness reactivity from baseline to the speech-task to later SAD symptoms $\left(\mathrm{T}_{6}\right), b[95 \% \mathrm{CI}]=0.22[0.07,0.56]$. This finding suggests that perceived stress reactivity in this phase of the PST was significantly associated with persistence of adolescent SAD symptoms over time.

\subsection{Developmental trajectory of SAD symptoms and cortisol reactivity}

See Table 4 for an overview of all results regarding associations between adolescents' developmental history of SAD symptoms $\left(\mathrm{T}_{1}-\mathrm{T}_{5}\right)$, cortisol reactivity during different phases of the PST, and later SAD symptoms $\left(\mathrm{T}_{6}\right)$. Because results with raw and logtransformed cortisol data were similar, we will only report on the models with raw data.

\subsubsection{SAD symptoms and anticipatory cortisol (from baseline to} the speech-task)

The SEM model showed acceptable to good fit, $\chi^{2}(33)=74.68$, $\mathrm{CFI}=0.94$, RMSEA $[90 \% \mathrm{CI}]=0.06[0.04,0.08]$, SRMR $=0.06$. Results suggested no significant longitudinal associations between adolescents' developmental history of SAD symptoms and cortisol reactivity in any of the phases of the PST, nor between cortisol reactivity in any of the phases of the PST and SAD symptoms at $\mathrm{T}_{6}$.

\subsubsection{SAD symptoms and cortisol recovery (from the speech-task to recovery)}

The SEM model showed acceptable to good fit, $\chi^{2}(33)=72.72$, $\mathrm{CFI}=0.96$, RMSEA $[90 \% \mathrm{CI}]=0.06[0.04,0.08]$, SRMR $=0.06$. Results suggested no significant longitudinal associations between adolescents' developmental history of SAD symptoms and cortisol reactivity in any of the phases of the PST, nor between cortisol reactivity in any of the phases of the PST and SAD symptoms at $\mathrm{T}_{6}$.

\subsubsection{Indirect effects}

Results suggested no significant longitudinal indirect effects for cortisol reactivity in any of the phases of the PST.

\subsection{Developmental trajectory of SAD symptoms and perceived heart rate reactivity}

See Table 4 for an overview of all results regarding associations between adolescents' developmental history of SAD symptoms $\left(\mathrm{T}_{1}-\mathrm{T}_{5}\right)$, perceived heart rate reactivity during different phases of the PST, and later SAD symptoms $\left(\mathrm{T}_{6}\right)$.

\subsubsection{SAD symptoms and perceived anticipatory heart rate (from} baseline to the speech-task)

The SEM model showed good fit, $\chi^{2}(1)=1.24, \mathrm{CFI}=1.00$, RMSEA $[90 \% \mathrm{CI}]=0.03[0.00,0.15], \mathrm{SRMR}=0.02$. Consistent with theoretical suggestions and past research, results suggested that adolescents in the Higher SAD subgroup showed greater increases in perceived heart rate from baseline to the speech-task, $\beta=0.70$. These greater increases in perceived heart rate from baseline to the speech-task were also significantly associated with higher SAD symptoms at $\mathrm{T}_{6}$, $\beta=0.16$. 
Table 4

Summary of Results from our Latent Difference Score Analyses.

\begin{tabular}{|c|c|c|}
\hline & $\begin{array}{l}\text { SAD symptoms }\left(T_{1}-T_{5}\right)^{\mathrm{a}} \text { predicting stress } \\
\text { reactivity and recovery during PST }\end{array}$ & $\begin{array}{l}\text { Stress reactivity and recovery during PST } \\
\text { predicting SAD symptoms }\left(\mathrm{T}_{6}\right)\end{array}$ \\
\hline \multicolumn{3}{|l|}{ Perceived nervousness } \\
\hline End baseline to Speech-task & $b[95 \% \mathrm{CI}]=1.24[0.42,2.04], \beta=0.62$ & $b[95 \% \mathrm{CI}]=\mathbf{0 . 1 8}[\mathbf{0 . 0 9}, \mathbf{0 . 3 2}], \boldsymbol{\beta}=\mathbf{0 . 2 5}$ \\
\hline Speech-task to Short-term recovery & $b[95 \% \mathrm{CI}]=\mathbf{0 . 7 9}[\mathbf{0 . 0 6}, \mathbf{1 . 5 2}], \boldsymbol{\beta}=\mathbf{0 . 1 8}$ & $b[95 \% \mathrm{CI}]=-0.01[-0.04,0.03], \beta=-0.02$ \\
\hline Short-term to Long-term recovery & $b[95 \% \mathrm{CI}]=0.08[-0.28,0.49], \beta=0.01$ & $\boldsymbol{b}[95 \% \mathrm{CI}]=-\mathbf{0 . 0 5}[-\mathbf{0 . 0 7},-\mathbf{0 . 0 2}], \boldsymbol{\beta}=-\mathbf{0 . 1 9}$ \\
\hline \multicolumn{3}{|l|}{ Perceived heart rate } \\
\hline End baseline to Speech-task & $b[95 \% C I]=0.92[0.11,1.69], \beta=0.70$ & $b[95 \% \mathrm{CI}]=\mathbf{0 . 1 8}[\mathbf{0 . 0 8 , 0 . 3 0 ] , \beta = 0 . 1 6}$ \\
\hline Speech-task to Short-term recovery & $b[95 \% \mathrm{CI}]=0.37[-0.20,0.99], \beta=0.05$ & $b[95 \% \mathrm{CI}]=-0.01[-0.04,0.01], \beta=-0.06$ \\
\hline Short-term to Long-term recovery & $b[95 \% \mathrm{CI}]=0.02[-0.39,0.52], \beta=0.00$ & $b[95 \% \mathrm{CI}]=-\mathbf{0 . 0 4}[-\mathbf{0 . 0 7},-\mathbf{0 . 0 1}], \boldsymbol{\beta}=-\mathbf{0 . 1 3}$ \\
\hline \multicolumn{3}{|l|}{ Cortisol } \\
\hline End baseline to Preparation & $b[95 \% \mathrm{CI}]=-0.03[-0.74,0.71], \beta=-0.01$ & $b[95 \% \mathrm{CI}]=-0.02[-0.69,0.16], \beta=-0.04$ \\
\hline Preparation to Speech-task & $b[95 \% \mathrm{CI}]=0.17[-0.63,0.94], \beta=0.09$ & $b[95 \% \mathrm{CI}]=-0.02[-0.68,0.27], \beta=-0.02$ \\
\hline Speech-task to Short-term recovery & $b[95 \% \mathrm{CI}]=0.27[-0.12,0.70], \beta=0.11$ & $b[95 \% \mathrm{CI}]=0.02[-0.15,0.24], \beta=0.04$ \\
\hline Short-term recovery to Long-term recovery & $b[95 \% \mathrm{CI}]=0.03[-0.52,0.51], \beta=0.01$ & $b[95 \% \mathrm{CI}]=-0.05[-0.27,0.11], \beta=-0.08$ \\
\hline \multicolumn{3}{|l|}{ Heart rate } \\
\hline End baseline to Instruction & $b[95 \% \mathrm{CI}]=\mathbf{0 . 3 4}[\mathbf{0 . 0 7}, \mathbf{0 . 6 4}], \boldsymbol{\beta}=\mathbf{0 . 1 7}$ & $b[95 \% \mathrm{CI}]=\mathbf{0 . 3 3}[\mathbf{0 . 0 9}, \mathbf{3 . 4 6}], \boldsymbol{\beta}=\mathbf{0 . 4 7}$ \\
\hline Instruction to Preparation & $b[95 \% \mathrm{CI}]=0.03[-0.13,0.16], \beta=0.04$ & $b[95 \% \mathrm{CI}]=\mathbf{1 . 4 2}[\mathbf{0 . 0 2}, \mathbf{1 6 . 1 1}], \boldsymbol{\beta}=\mathbf{0 . 6 4}$ \\
\hline Preparation to Audience entering & $b[95 \% \mathrm{CI}]=0.08[-0.12,0.29], \beta=0.05$ & $b[95 \% \mathrm{CI}]=0.38[-0.16,6.73], \beta=0.39$ \\
\hline Audience entering to Speech-task & $b[95 \% \mathrm{CI}]=-0.06[-0.34,0.23], \beta=-0.03$ & $b[95 \% \mathrm{CI}]=0.05[-0.23,2.99], \beta=0.07$ \\
\hline Speech-task to Short-term recovery & $b[95 \% \mathrm{CI}]=-\mathbf{0 . 2 6}[-\mathbf{0 . 5 2},-\mathbf{0 . 0 1}], \boldsymbol{\beta}=-\mathbf{0 . 1 1}$ & $b[95 \% \mathrm{CI}]=0.02[-0.06,0.10], \beta=0.03$ \\
\hline Short-term to Long-term recovery & $b[95 \% \mathrm{CI}]=0.07[-0.09,0.22], \beta=0.07$ & $b[95 \% \mathrm{CI}]=-\mathbf{0 . 1 7}[-\mathbf{0 . 3 3},-\mathbf{0 . 0 1}], \boldsymbol{\beta}=-\mathbf{0 . 1 2}$ \\
\hline
\end{tabular}

Note. Significant associations are presented in bold.

a Referring to individuals' posterior probabilities for the Higher SAD subgroup.

\subsubsection{SAD symptoms and perceived heart rate recovery (from the} speech-task to recovery)

The SEM model showed good fit, $\chi^{2}(3)=2.73, \mathrm{CFI}=1.00$, RMSEA $[90 \% \mathrm{CI}]=0.00[0.00,0.09], \mathrm{SRMR}=0.02$. Results suggested no significant longitudinal associations between adolescents' developmental history of SAD symptoms and perceived heart rate recovery, but that stronger decreases in perceived heart rate from short-term recovery to long-term recovery were significantly associated with higher SAD symptoms at $\mathrm{T}_{6}, \beta=-0.13$.

\subsubsection{Indirect effects}

A significant indirect effect was found for adolescents in the Higher SAD subgroup $\left(\mathrm{T}_{1}-\mathrm{T}_{5}\right)$ via increased perceived heart rate reactivity from baseline to the speech-task to later SAD symptoms $\left(\mathrm{T}_{6}\right), b[95 \% \mathrm{CI}]=0.16[0.03,0.41]$. This finding suggests that perceived heart rate reactivity in this phase of the PST was significantly associated with persistence of adolescent SAD symptoms over time.

\subsection{Developmental trajectory of SAD symptoms and heart rate reactivity}

See Table 4 for an overview of all results regarding associations between adolescents' developmental history of SAD symptoms $\left(\mathrm{T}_{1}-\mathrm{T}_{5}\right)$, heart rate reactivity during different phases of the PST, and later SAD symptoms $\left(\mathrm{T}_{6}\right)$.

\subsubsection{SAD symptoms and anticipatory heart rate (from baseline to the speech-task)}

The SEM model showed good fit, $\chi^{2}(9)=11.04, \mathrm{CFI}=1.00$, RMSEA $[90 \% \mathrm{CI}]=0.03[0.00,0.07], \mathrm{SRMR}=0.07$. Results suggested that adolescents in the Higher SAD subgroup showed greater increases in heart rate from baseline to the instruction phase, $\beta=0.17$, but not in any of the other phases up to the speech-task. Furthermore, greater increases in heart rate from baseline to the instruction phase as well as from the instruction to the preparation phase were significantly associated with higher SAD symptoms at $\mathrm{T}_{6}, \beta=0.47$ and $\beta=0.64$, respectively.

\subsubsection{SAD symptoms and heart rate recovery (from the} speech-task to recovery)

The SEM model showed acceptable to good fit, $\chi^{2}(2)=13.50$, $\mathrm{CFI}=0.99$, RMSEA $[90 \% \mathrm{CI}]=0.13[0.07,0.20]$, SRMR $=0.04$. Results suggested that adolescents in the Higher SAD subgroup showed greater decreases in heart rate from the speech task to short-term recovery, $\beta=-0.11$. Furthermore, greater decreases in heart rate from short-term recovery to long-term recovery were significantly associated with SAD symptoms at $\mathrm{T}_{6}, \beta=-0.12$.

\subsubsection{Indirect effects}

A significant indirect effect was found for adolescents in the Higher SAD subgroup $\left(T_{1}-T_{5}\right)$ via increased heart rate reactivity from baseline to the speech-task to later SAD symptoms $\left(\mathrm{T}_{6}\right), b$ $[95 \% \mathrm{CI}]=0.11[0.02,1.50]$. This finding suggests that heart rate reactivity in this phase of the PST was significantly associated with persistence of adolescent SAD symptoms over time.

\subsection{Specificity analyses: $T_{5} S A D$ symptoms, stress reactivity, and $T_{6}$ SAD symptoms}

To examine the specificity of our findings, we have run additional analyses examining associations between $T_{5}$ SAD symptoms (instead of 5-year SAD symptom trajectories), perceived and physiological stress reactivity, and $\mathrm{T}_{6}$ SAD symptoms. All SEM models showed acceptable to good fit, CFIs $=0.96-1.00$, RMSEAs $[90 \%$ CIs] $=0.00-0.14[0.00-0.10,0.00-0.19]$, SRMRs $=0.01-0.09$. An overview of all results is shown in Table 5.

Results from these additional analyses showed strong resemblance to the results concerning associations between adolescents' developmental history of SAD symptoms $\left(T_{1}-T_{5}\right)$, stress reactivity, and $\mathrm{T}_{6}$ SAD symptoms. Importantly, results were consistent in showing that $(i)$ higher levels of $T_{5}$ SAD symptoms were associated with stronger increases in both perceived nervousness and perceived heart rate from baseline to the speech-task and that stronger increases in both perceived nervousness and perceived heart rate from baseline to the speech-task were, in turn, significantly associated with higher $T_{6}$ SAD symptoms (including significant indirect effects), (ii) higher levels of $T_{5}$ SAD symptoms were associated with 
Table 5

Summary of Results from our Additional Latent Difference Score Analyses Focusing on $\mathrm{T}_{5}$ SAD symptoms.

\begin{tabular}{|c|c|c|}
\hline & $\begin{array}{l}\text { SAD symptoms } T_{5} \text { predicting stress reactivity } \\
\text { and recovery during PST }\end{array}$ & $\begin{array}{l}\text { Stress reactivity and recovery during PST } \\
\text { predicting SAD symptoms } T_{6}\end{array}$ \\
\hline \multicolumn{3}{|l|}{ Perceived nervousness } \\
\hline End baseline to Speech-task & $b[95 \% \mathrm{CI}]=1.14[0.52,1.72], \beta=0.78$ & $b[95 \% \mathrm{CI}]=\mathbf{0 . 0 4}[0.01,0.08], \boldsymbol{\beta}=0.05$ \\
\hline Speech-task to Short-term recovery & $b[95 \% \mathrm{CI}]=0.43[0.04,0.77], \beta=0.14$ & $b[95 \% \mathrm{CI}]=-0.01[-0.04,0.02], \beta=-0.03$ \\
\hline Short-term to Long-term recovery & $b[95 \% \mathrm{CI}]=0.05[-0.14,0.31], \beta=0.01$ & $b[95 \% \mathrm{CI}]=-0.02[-0.04,0.01], \beta=-0.06$ \\
\hline \multicolumn{3}{|l|}{ Perceived heart rate } \\
\hline End baseline to Speech-task & $b[95 \% \mathrm{CI}]=\mathbf{0 . 8 8}[\mathbf{0 . 2 6}, \mathbf{1 . 4 7}], \boldsymbol{\beta}=\mathbf{0 . 5 7}$ & $\boldsymbol{b}[95 \% \mathrm{CI}]=\mathbf{0 . 0 3}[\mathbf{0 . 0 0 , 0 . 0 5}], \boldsymbol{\beta}=\mathbf{0 . 0 4}$ \\
\hline Speech-task to Short-term recovery & $b[95 \% \mathrm{CI}]=0.12[-0.23,0.46], \beta=0.02$ & $b[95 \% \mathrm{CI}]=-0.01[-0.03,0.01], \beta=-0.05$ \\
\hline Short-term to Long-term recovery & $b[95 \% \mathrm{CI}]=0.09[-0.21,0.43], \beta=0.02$ & $b[95 \% \mathrm{CI}]=-0.01[-0.04,0.01], \beta=-0.05$ \\
\hline \multicolumn{3}{|l|}{ Cortisol } \\
\hline End baseline to Preparation & $b[95 \% \mathrm{CI}]=0.02[-0.55,0.64], \beta=0.01$ & $b[95 \% \mathrm{CI}]=0.04[-0.04,0.25], \beta=0.08$ \\
\hline Preparation to Speech-task & $b[95 \% \mathrm{CI}]=0.20[-0.32,0.74], \beta=0.15$ & $b[95 \% \mathrm{CI}]=0.03[-0.36,0.16], \beta=0.04$ \\
\hline Speech-task to Short-term recovery & $b[95 \% \mathrm{CI}]=0.06[-0.28,0.42], \beta=0.03$ & $b[95 \% \mathrm{CI}]=0.04[-0.08,0.31], \beta=0.06$ \\
\hline Short-term recovery to Long-term recovery & $b[95 \% \mathrm{CI}]=-0.28[-0.78,0.17], \beta=-0.17$ & $b[95 \% \mathrm{CI}]=-0.06[-0.24,0.07], \beta=-0.10$ \\
\hline \multicolumn{3}{|l|}{ Heart rate } \\
\hline End baseline to Instruction & $\boldsymbol{b}[95 \% \mathrm{CI}]=\mathbf{0 . 3 7}[\mathbf{0 . 1 3}, \mathbf{0 . 6 4}], \boldsymbol{\beta}=\mathbf{0 . 2 5}$ & $b[95 \% \mathrm{CI}]=0.22[0.06,1.44], \beta=0.31$ \\
\hline Instruction to Preparation & $b[95 \% \mathrm{CI}]=-0.09[-0.21,0.02], \beta=-0.19$ & $b[95 \% \mathrm{CI}]=\mathbf{1 . 0 6}[\mathbf{0 . 0 8}, \mathbf{6 . 4 5}], \boldsymbol{\beta}=\mathbf{0 . 4 8}$ \\
\hline Preparation to Audience entering & $b[95 \% \mathrm{CI}]=0.09[-0.05,0.24], \beta=0.08$ & $b[95 \% \mathrm{CI}]=0.17[-0.22,2.50], \beta=0.17$ \\
\hline Audience entering to Speech-task & $b[95 \% \mathrm{CI}]=-0.05[-0.24,0.13], \beta=-0.04$ & $b[95 \% \mathrm{CI}]=-0.04[0.27,1.03], \beta=-0.05$ \\
\hline Speech-task to Short-term recovery & $b[95 \% \mathrm{CI}]=-0.09[-0.27,0.09], \beta=-0.05$ & $b[95 \% \mathrm{CI}]=0.04[-0.03,0.10], \beta=0.06$ \\
\hline Short-term to Long-term recovery & $b[95 \% \mathrm{CI}]=-0.07[-0.18,0.05], \beta=-0.07$ & $b[95 \% \mathrm{CI}]=-0.07[-0.17,0.04], \beta=-0.07$ \\
\hline
\end{tabular}

Note. Significant associations are presented in bold.

a slower decrease (i.e., stronger persistence) in perceived nervousness from the speech-task to short-term recovery, (iii) higher levels of $\mathrm{T}_{5}$ SAD symptoms were associated with greater increases in heart rate from baseline to the instruction phase and that greater increases in heart rate from baseline to the instruction phase were significantly associated with higher $\mathrm{T}_{6}$ SAD symptoms (including a significant indirect effect), (iv) higher levels of $T_{5}$ SAD symptoms were associated with greater increases in heart rate from the instruction to the preparation phase were significantly associated with higher SAD symptoms at $\mathrm{T}_{6}$, and that $(v)$ there were no significant associations between adolescent SAD symptoms and cortisol reactivity in any of the phases of the PST.

\section{Discussion}

The goal of the present study was to focus on short-term psychological and physiological processes that may be associated with long-term stability of SAD symptoms in adolescents from the general population, thereby trying to uncover potential developmental mechanisms underlying the persistence of adolescent SAD symptoms over time. To our knowledge, this study is the first direct empirical tests of theory (Clark and Wells, 1995) on the assumed important role of both perceived and physiological stress reactivity in the persistence of SAD symptoms in adolescents from the general population. Specifically, we examined how perceived (i.e., self-reported nervousness and heart rate) and physiological (i.e., cortisol and heart rate) stress reactivity during different phases of a PST were associated with persistence of adolescent SAD symptoms from early to late adolescence. Most importantly, findings suggested that greater increases in perceived nervousness and perceived heart rate from baseline to the stress-task as well as greater increases in heart rate from baseline to anticipation of the stresstask were associated with persistence of adolescent SAD symptoms over time. These findings point to a developmental process in which a developmental history of higher and persistent SAD symptoms is associated with heightened sensitivity to socially stressful situations, which, in turn, is associated with future symptoms of SAD. This self-reinforcing process in which state symptoms of psychological distress as well as physiological arousal and trait symptoms of SAD appear to reinforce each other over time provides important insights in the general persistence of adolescent SAD symptoms.

\subsection{SAD and perceived stress reactivity}

Our findings suggest that a developmental history of higher adolescent SAD symptoms is strongly associated with heightened perceived stress reactivity, which, in turn, is associated with later adolescent symptoms of SAD. These results are in line with previous cross-sectional studies (see Siess et al., 2014) and extend earlier findings to long-term longitudinal associations in adolescents using a dimensional approach of SAD. Moreover, these results provide empirical support for adult models on the persistence of SAD (Clark \& Wells, 1995; Rapee \& Heimberg, 1997) in adolescents from the general population. This model suggests that individuals with high levels of SAD symptoms engage in a variety of negatively biased cognitive processes in anticipation of feared social situations, which are associated with strong increases in psychological distress. Several interlinked self-reinforcing processes then prevent disconfirmation of these negative biases and maintain the individual's distress in the short-term. In turn, these individuals are more likely to interpret the situation as posing a threat, which reinforces their fear of such situations in the future. This negative spiral is theorized to play a critical role in SAD symptom persistence in the long-term. Higher SAD symptoms in adolescents thus seem to go together with a vulnerability to experience strong increases (i.e., heightened reactivity) in state symptoms of psychological distress when faced with a feared social-performance situation, which appears to be associated with persistence in trait levels of adolescent SAD symptoms over time.

Additionally, we found some evidence that a developmental history of higher SAD symptoms was associated with sustained feelings of nervousness in the short-term. This finding is consistent with theoretical suggestions that the ending of a feared socialperformance situation may not necessarily bring an immediate end to the negative thoughts and (ruminative) distress of individuals with high levels of SAD symptoms, also referred to as post-event processing (Clark \& Wells, 1995). Our finding is also in line with previous research (Krämer et al., 2012; Schmitz et al., 2011), although only few studies have included recovery phases in their study 
design. At the same time, we also found that stronger decreases in feelings of nervousness after this initial sustained period of distress as well as stronger decreases in perceived heart rate at the end of the recovery phase were associated with later SAD symptoms. This suggests strong fluctuations in experiences of distress for adolescents with a developmental history of higher levels of SAD symptoms around social-performance situations. Some studies have suggested that strong fluctuations in mood and emotions (i.e., heightened mood or emotional variability) may drive adolescent anxiety development (e.g., Maciejewski et al., 2014; Neumann, Van Lier, Frijns, Meeus, \& Koot, 2011). Our pattern of findings may illustrate part of the process underlying this heightened mood or emotional variability in adolescent SAD symptoms. Specifically, strong reactivity to social stressors may underlie heightened mood or emotional variability, which may account for development and persistence of adolescent SAD symptoms over time.

\section{2. $S A D$ and physiological stress reactivity}

In line with the theory of Clark \& Wells (1995), our results also suggested a role of heart rate reactivity in the persistence of adolescent SAD symptoms over time, with positive longitudinal associations between adolescent SAD symptoms and increases in heart rate from baseline to anticipation of the PST. Interestingly, SAD symptoms were not significantly associated with further increases in heart rate after this anticipatory phase, although greater increases in heart rate from anticipation to preparation of the speech-task were significantly associated with later SAD symptoms. These results emphasize the importance of detailed examination of stress reactivity in different phases of a PST. Although most youth are expected to show a degree of increased psychological distress and physiological activity during a PST, which was also found in our study, stress reactivity in anticipation of a (socially) stressful situation was specifically associated with adolescent SAD symptoms. This finding was not unexpected, as SAD involves the emotional state that arises when potential future danger or threat in social-performance situations is anticipated and SAD symptoms thus involve an anticipatory state (Barlow, 2002; Grupe \& Nitschke, 2013). Several interlinked self-reinforcing processes that maintain the individual's distress in the short-term may subsequently fuel SAD symptom persistence in the long-term (Clark \& Wells, 1995).

Although our findings are consistent with these theoretical suggestions, previous studies have generally not found associations between SAD symptoms and heart rate reactivity (see Siess et al., 2014). Given that only few studies have focused on stress reactivity in anticipation of a stress-task and have generally been conducted in much smaller samples, previous studies may have failed to detect associations between SAD symptoms and heart rate reactivity. Moreover, it may be important to take adolescents' developmental history of SAD symptoms into account when studying their short-term responses to a stressful situation. At the same time, associations between SAD symptoms and greater heart rate reactivity may apply only to adolescents from the general population, since heightened physiological stress reactivity has generally not been found in clinical samples of youth (Alkozei, Creswell, Cooper, \& Allen, 2015; Siess et al., 2014).

The fact that we found moderate associations between SAD symptoms and heart rate reactivity but not cortisol reactivity may further suggest that the fast-responding ANS and the slowresponding HPA-axis might be differentially involved-with a more important role of immediate cardiac-responses than slower hormonal responses-in the persistence of adolescent symptoms of SAD. We should, however, be cautious with this interpretation, because the PST used in our study has shown to produce a relatively modest cortisol response and a relatively large proportion of non-responders (Westenberg et al., 2009) in comparison to other studies. Other stress protocols, such as the Trier Social Stress Test that includes an impromptu speech-task, that have been found to consistently trigger substantial HPA-axis activation in most people (Dickerson \& Kemeny, 2004), might be more suitable to specifically investigate HPA-axis reactivity (Westenberg et al., 2009). Alternatively, we may not have sampled cortisol frequently enough to observe the anticipated increase in salivary cortisol during the speech-task, in line with suggestions by Martel et al. (1999). Due to a delay in peak levels of cortisol in saliva, samples generally reflect neuroendocrine activity approximately $20 \mathrm{~min}$. earlier (Dickerson \& Kemeny, 2004; Westenberg et al., 2009), but large individual differences are possible. Finally, the HPA-axis is a self-regulating system that decreases its own activity through a negative feedback loop (i.e., down-regulation) to protect against prolonged exposure to elevated cortisol. As associations in our study were longitudinal, covering at least a few months, it could potentially be that more concurrent associations between adolescent SAD symptoms and cortisol reactivity were not captured in our study. Clearly, more work on associations between adolescent SAD symptoms and cortisol reactivity during social-performance situations is needed.

\subsection{Additional specificity analyses}

Interestingly, findings from our additional specificity analyses focusing on $T_{5}$ SAD symptoms, stress reactivity, and $T_{6} S A D$ symptoms showed strong resemblance to findings from our main analyses focusing on adolescents' developmental history of SAD symptoms across 5 successive years. Findings from both a personcentered approach focusing on persistence in SAD symptoms across several years and a variable-centered approach focusing on SAD symptoms at one point in time thus appear to point to a developmental process in which SAD symptoms are associated with heightened sensitivity to socially stressful situations, which, in turn, is associated with future symptoms of SAD. Because findings from both approaches support the theoretical model on SAD symptom persistence (Clark \& Wells, 1995; Rapee \& Heimberg, 1997), this suggests that similar mechanisms appear to be underlying SAD symptom persistence for adolescents presented with long-term heightened SAD symptoms and adolescents with heightened SAD symptoms at one moment in time. Importantly, future research studying stress reactivity as process underlying SAD symptom persistence may thus not necessarily need to include such an intensive longitudinal design focusing on adolescents' developmental history of SAD symptoms across several years as in our study. At the same time, some meaningful differences between our main analyses and our additional analyses should be acknowledged. Importantly, the consistent pattern of findings suggesting that stronger decreases in perceived nervousness, perceived heart rate, and actual heart rate at the end of the recovery period were associated with later SAD symptoms in our main analyses did not show in our additional analyses. This suggests that even stronger fluctuations in experiences of psychological distress and physiological activity appear to drive persistence in SAD symptoms for those adolescents with already persistent high levels of SAD symptoms across several years compared to those with high levels of SAD symptoms at only one moment in time. Both approaches may thus provide important unique insights in adolescent SAD symptom persistence.

\subsection{Strengths, limitations, and suggestions for future research}

An important strength of this study is its 6-year prospective longitudinal design in a large community sample of adolescents, which makes it particularly suitable to study normative processes that may be associated with the development and stability of SAD symptoms over time before clinical levels have been reached. Our 
study provides a strong test of longitudinal associations between adolescent SAD symptoms and stress reactivity, by: (i) combining adolescent self-reported data on SAD symptoms over six successive years with both self-reported and physiological measures of stress reactivity taken during different phases of an experimental stress-task, (ii) simultaneously examining indicators of the ANS and HPA-axis, (iii) using a dimensional approach to SAD symptoms, and (iv) using latent difference scores to accurately capture changes in psychological distress and physiological activity. Overall, we used a novel approach to study the role of both perceived and physiological stress reactivity in the long-term persistence of adolescent SAD symptoms. Hence, our study represents a novel attempt to uncover perceived and physiological mechanisms of SAD symptom development, which may be an important direction for future research in human development more in general.

Our study, however, also has some limitations, which may provide some important directions for future research. First, although our longitudinal models do not allow for any causal conclusions, theoretical models do assume a causal role of the examined processes in the persistence of SAD symptoms over time (Clark \& Wells, 1995; Rapee \& Heimberg, 1997). Second, although this study was comprehensive in including two measures of both perceived stress reactivity (i.e., self-reported nervousness and heart rate) and physiological stress reactivity (i.e., cortisol and heart rate) during different phases of a PST, these measures still represent only a limited breadth of markers of stress reactivity. Future research may want to conduct a more in-depth investigation of especially physical measures of stress reactivity, for example by specifically distinguishing between the sympathetic (SNS) and parasympathetic (PNS) branches of the ANS (see e.g., Alkozei et al., 2015; Dietrich et al., 2007; Greaves-Lord et al., 2010). Measures such as PEP (Pre-Ejection Period) and RSA (Respiratory Sinus Arrhythmia) can be more directly related to either SNS or PNS activity, respectively, which may provide a more detailed picture regarding the role of (dysregulation in) these branches in the development and persistence of adolescent SAD symptoms.

Third, future research could improve upon several aspects of our study. Importantly, we have not assessed distress during the theoretically most salient anticipatory phase (Clark \& Wells, 1995). For future research it would be important to include assessments of both psychological distress and physiological activity particularly in anticipation of a stressful social-performance situation. Furthermore, despite playing a central role in theoretical models on the persistence of SAD symptoms over time (Clark \& Wells, 1995; Rapee \& Heimberg, 1997), we cannot rule out that our assessments of psychological distress shows some overlap with adolescent SAD symptoms because both were self-reported (although correlations between these measures were only moderate at best; see Table 3). In future research it may be important to replicate our results using other- or multi-informant assessments of adolescent SAD symptoms. Also, we were not able to control for prescription medication use that may have altered cortisol levels (Adam \& Kumari, 2009; Kudielka \& Wüst, 2010), which would be important for future research to include in the analyses. Finally, our sample was relatively homogenous, including only ethnic Dutch adolescents from intact two-parent families with relatively high SES (based on parents' job level) at the start of the study. Hence, caution should be exercised when generalizing our findings.

Fourth, the protocol of the Leiden PST includes participants watching a nature documentary before and after the speech-task to allow for adequate assessment of baseline and recovery physical stress levels. However, it is unclear how watching a nature documentary, which might be considered as a type of relaxation technique, might affect associations between adolescent SAD symptoms and stress reactivity, especially after the speech-task. Therefore, in future research it would be important to examine how watching this particular type of nature documentary might affect psychological distress and physiological activity levels, particularly in adolescents with high levels of SAD symptoms, and explore potential alternative "activities" that might be considered less of a relaxation but would still allow for an extensive assessment period of baseline and recovery levels.

Fifth and finally, even though our design is longitudinal, stress reactivity was only assessed once in late adolescence. Future studies may want to examine this developmental processes underlying the development and persistence of SAD symptoms earlier in adolescence, especially because a potentially important role of puberty has been implied in the development of SAD symptoms as well as heightened stress reactivity, particularly for girls (Reardon, LeenFeldner, \& Hayward, 2009; Van den Bos, De Rooij, Miers, Bokhorst, \& Westenberg, 2014). Also, future research may want to consider researching children of even younger ages. Such research could focus on childhood factors that have found to be strongly associated with later SAD symptoms, such as levels of behavioral inhibition (Hirshfeld-Becker, Biederman, \& Rosenbaum, 2004) or anxious solitude (Gazelle, Workman, \& Allan, 2010), and the role of stress reactivity in persistence of these constructs over time and/or in the prediction of adolescent SAD symptoms.

\section{Conclusion}

To our knowledge, this study represents the first direct empirical test of adult theory (Clark \& Wells, 1995) on the importance of perceived and physiological stress reactivity in the persistence of SAD symptoms over time. Adolescence is a particularly significant period to study both perceived and physiological stress-related processes that may be involved in the development and persistence of SAD symptoms over time, because this is a crucial period for the development of SAD symptoms and is characterized by major cognitive changes and physiological changes as well (Spear, 2009; Steinberg, 2005). From our findings we may tentatively conclude that results support theory regarding the importance of both perceived stress reactivity and heart rate reactivity in the persistence (and worsening) of adolescent SAD symptoms over time, suggesting a self-reinforcing process that maintains adolescent SAD symptoms. By combining self-report data from our long-term longitudinal community study with perceived and physiological measures taken during an experimental setting, our study represents an initial attempt to uncover mechanisms of development, which may be an important direction for future research. Although we should be cautious in discussing potential clinical implications of our findings, these findings might inform prevention and intervention programs aimed to reduce adolescent SAD symptoms to specifically target adolescents' (perceived) experiences of distress in anticipation of, and during, socially stressful situations because of their apparent important role in maintaining (and worsening) SAD symptoms over time. Clearly, however, more work is needed to understand short-term psychological and physical processes involved in the long-term stability of (adolescent) SAD symptoms in the general population.

\section{References}

Adam, E. K., \& Kumari, M. (2009). Assessing salivary cortisol in large-scale, epidemiological research. Psychoneuroendocrinology,, 34, 1423-1436. http://dx. doi.org/10.1016/j.psyneuen.2009.06.011

Alkozei, A., Creswell, C., Cooper, P. J., \& Allen, J. J. B. (2015). Autonomic arousal in childhood anxiety disorders: Associations with state anxiety and social anxiety disorder. Journal of Affective Disorders, 175, 25-33. http://dx.doi.org/10.1016/j. jad.2014.11.056

American Psychiatric Association. (2013). Diagnostic and statistical manual of mental disorders (5th ed.). Washington, DC: Author.

Anderson, E. R., \& Hope, D. A. (2009). The relationship among social phobia, objective and perceived physiological reactivity, and anxiety sensitivity in an 
adolescent population. Journal of Anxiety Disorders, 23, 18-26. http://dx.doi. org/10.1016/j.janxdis.2008.03.011

Barlow, D. H. (2002). Anxiety and its disorders: The nature and treatment of anxiety and panic. New York: Guilford.

Birmaher, B., Khetarpal, S., Brent, D., Cully, M., Balach, L., Kaufman, J., \& Neer, S. M. (1997). The Screen for Child Anxiety Related Emotional Disorders (SCARED): Scale construction and psychometric characteristics. Journal of the American Academy of Child and Adolescent Psychiatry, 36, 545-553.

Cicchetti, D., \& Rogosch, F. A. (2002). A developmental psychopathology perspective on adolescence. Journal of Consulting and Clinical Psychology, 70 , 6-20. http://dx.doi.org/10.1037//0022-006X.70.1.6

Clark, D. M., \& Wells, A. (1995). A cognitive model of social phobia. In R. Heimberg, M. Liebowitz, D. A. Hope, \& F. R. Schneier (Eds.), Social phobia: Diagnosis, assessment and treatment (pp. 69-93). New York: Guilford Press.

Coles, M. E., \& Heimberg, R. G. (2000). Patterns of anxious arousal during exposure to feared situations in individuals with social phobia. Behaviour Research and Therapy, 38, 405-424. http://dx.doi.org/10.1016/S0005-7967(99)00092-3

Davey, H. M., Barratt, A. L., Butow, P. N., \& Deeks, J. J. (2007). A one-item question with a Likert or Visual Analog Scale adequately measured current anxiety. Journal of Clinical Epidemiology, 60, 356-360. http://dx.doi.org/10.1016/j. jclinepi.2006.07.015

Dickerson, S. S., \& Kemeny, M. E. (2004). Acute stressors and cortisol responses: A theoretical integration and synthesis of laboratory research. Psychological Bulletin, 130, 355-391. http://dx.doi.org/10.1037/0033-2909.130.3.355

Dietrich, A., Riese, H., Sondeijker, F. E. P. L., Greaves-Lord, K., Van Roon, A. M. Ormel, J., . . \& \& Rosmalen, J. G. M. (2007). Externalizing and internalizing problems in relation to autonomic function: A population-based study in preadolescents. Journal of the American Academy of Child and Adolescent Psychiatry, 46, 378-386. http://dx.doi.org/10.1097/CHI.0b013e31802b91ea

Gazelle, H., Workman, J. O., \& Allan, W. (2010). Anxious solitude and clinical disorder in middle childhood: Bridging developmental and clinical approaches to childhood social anxiety. Journal of Abnormal Child Psychology, 38, 1-17. http://dx.doi.org/10.1007/s10802-009-9343-z

Greaves-Lord, K., Tulen, J., Dietrich, A., Sondeijker, F. E. P. L., Van Roon, A. M., Oldehinkel, A., ... \& \&uizink, A. (2010). Reduced autonomic flexibility as a predictor for future anxiety in girls from the general population: The TRAILS study. Psychiatry Research, 179, 187-193. http://dx.doi.org/10.1016/j.psychres 2009.04.014

Grupe, D. W., \& Nitschke, J. B. (2013). Uncertainty and anticipation in anxiety: An integrated neurobiological and psychological perspective. Nature Reviews Neuroscience, 14, 488-501. http://dx.doi.org/10.1038/nrn3524

Hale, W. W., III, Raaijmakers, Q. A. W., Muris, P., \& Meeus, W. H. J. (2005). Psychometric properties of the Screen for Child Anxiety Related Emotional Disorders (SCARED) in the general adolescent population. Journal of the American Academy of Child and Adolescent Psychiatry, 44, 283-290. http://dx. doi.org/10.1097/00004583-200503000-00013

Hirshfeld-Becker, D. R., Biederman, J., \& Rosenbaum, J. F. (2004). Behavioral inhibition. In T. L. Morris, \& J. S. March (Eds.), Anxiety disorders in children and adolescents (pp. 27-58). New York, NY: Guildford Press.

Hollenstein, T., \& Lanteigne, D. (2014). Models and methods of emotional concordance. Biological Psychology, 98, 1-5. http://dx.doi.org/10.1016/j. biopsycho.2013.12.012

Hu, L. \& Bentler, P. M. (1999). Cutoff criteria for fit indexes in covariance structure analysis: Conventional criteria versus new alternatives. Structural Equation Modeling, 6, 1-55. http://dx.doi.org/10.1080/10705519909540118

Kessler, R. C., Berglund, P., Demler, O., Jin, R., Merikangas, K. R., \& Walters, E. E. (2005). Lifetime prevalence and age-of-onset distributions of DSM-IV disorders in the national comorbidity survey replication. Archives of General Psychiatry, 62, 593-602. http://dx.doi.org/10.1001/archpsyc.62.6.593

Kessler, R. C., Avenevoli, S., Costello, E. J., Georgiades, K., Green, J. G., Gruber, M. J., . \& Merikangas, K. R. (2012). Prevalence, persistence, and sociodemographic correlates of DSM-IV disorders in the National Comorbidity Survey Replication-Adolescent Supplement. Archives of General Psychiatry, 69 372-380. http://dx.doi.org/10.1001/archgenpsychiatry.2011.160

Kline, R. B. (2005). Principles and practice of structural equation modeling (2nd ed.). New York: Guilford.

Krämer, M., Seefeldt, W. L., Heinrichs, N., Tuschen-Caffier, B., Schmitz, J., Wolf, O. T., \& Blechert, J. (2012). Subjective, autonomic, and endocrine reactivity during social stress in children with social phobia. Journal of Abnormal Child Psychology, 40, 95-104. http://dx.doi.org/10.1007/s10802-011-9548-9

Kudielka, B. M., \& Wüst, S. (2010). Human models in acute and chronic stress: Assessing determinants of individual hypothalamus-pituitary-adrenal axis activity and reactivity. Stress, 13,1-14. http://dx.doi.org/10.3109/ 10253890902874913

Lanteigne, D. M., Flynn, J. J., Eastabrook, J. M., \& Hollenstein, T. (2014). Discordant patterns among emotional experience, arousal, and expression in adolescence: Relations with emotion regulation and internalizing problems. Canadian Journal of Behavioural Science, 46, 29-39. http://dx.doi.org/10.1037/a0029968

Maciejewski, D. F., Van Lier, P. A. C., Neumann, A., Van der Giessen, D., Branje, S. J. T., Meeus, W. H. J., \& Koot, H. M. (2014). The development of adolescent generalized anxiety and depressive symptoms in the context of adolescent mood variability and parent-adolescent negative interactions. Journal of Abnormal Child Psychology, 42, 515-526. http://dx.doi.org/10.1007/s10802013-9797-x

MacKinnon, D. P., Lockwood, C. M., \& Williams, J. (2004). Confidence limits for the indirect effect: Distribution of the product and resampling methods.
Multivariate Behavioral Research, 39, 99-128. http://dx.doi.org/10.1207/ s15327906mbr3901_4

Martel, E. L., Hayward, C., Lyons, D. M., Sanborn, K., Varady, S., \& Schatzberg, A. F. (1999). Salivary cortisol levels in socially phobic adolescent girls. Depression and Anxiety, 10, 25-27. http://dx.doi.org/10.1002/(SICI)15206394(1999)10:1<25:AID-DA4>3.0.CO;2-O

Mauss, I., Wilhelm, F., \& Gross, J. (2004). Is there less to social anxiety than meets the eye? Emotion experience, expression, and bodily responding. Cognition and Emotion, 18, 631-662. http://dx.doi.org/10.1080/02699930341000112

Mauss, I. B., Levenson, R. W., McCarter, L., Wilhelm, F. H., \& Gross, J. J. (2005). The tie that binds? Coherence among emotion experience, behavior and physiology. Emotion, 5, 175-190. http://dx.doi.org/10.1037/1528-3542.5.2.175

McArdle, J. J. (2009). Latent variable modeling of differences and changes with longitudinal data. Annual Review of Psychology, 60, 577-605. http://dx.doi.org/ 10.1146/annurev.psych.60.110707.163612

Merikangas, K. R., He, J., Burstein, M., Swanson, S. A., Avenevoli, S., Cui, L., .. \& \& Swendsen, J. (2010). Lifetime prevalence of mental disorders in U.S. adolescents: Results from the National Comorbidity Survey Replication -Adolescent Supplement (NCS-A). Journal of the American Academy of Child and Adolescent Psychiatry, 49, 980-989. http://dx.doi.org/10.1016/j.jaac.2010.05. 017

Muris, P., Merckelbach, H., Ollendick, T., King, N., \& Bogie, N. (2002). Three traditional and three new childhood anxiety questionnaires: Their reliability and validity in a normal adolescent sample. Behaviour Research and Therapy, 40, 753-772. http://dx.doi.org/10.1016/S0005-7967(01)00056-0

Muris, P., Dreessen, L., Bögels, S., Weckx, M., \& Van Melick, M. (2004). A questionnaire for screening a broad range of DSM-defined anxiety disorder symptoms in clinically referred children and adolescents. Journal of Child Psychology and Psychiatry, 45, 813-820. http://dx.doi.org/10.1111/j. 14697610.2004.00274.x

Muthén, L. K., \& Muthén, B. O. (2012). Mplus user's guide (7th ed.). Los Angeles: Muthén \& Muthén.

Nagin, D. S. (2005). Group based modeling of development. Cambridge: Harvard University Press.

Nelemans, S. A., Hale, W. W., III, Branje, S. J. T., Raaijmakers, Q. A. W., Frijns, T., Van Lier, P. A. C., \& Meeus, W. H. J. (2014). Heterogeneity in development of adolescent anxiety disorder symptoms in an 8-year longitudinal community study. Development and Psychopathology, 26, 181-202. http://dx.doi.org/10. 1017/S0954579413000503

Neumann, A., Van Lier, P. A. C., Frijns, T., Meeus, W. H. J., \& Koot, H. M. (2011). Emotional dynamics in the development of early adolescent psychopathology: A one-year longitudinal study. Journal of Abnormal Child Psychology, 39, 657-669. http://dx.doi.org/10.1007/s10802-011-9509-3

Ogliari, A., Scaini, S., Kofler, M. J., Lampis, V., Zanoni, A., Pesenti-Gritti, P., . . \& \& Beidel, D. C. (2012). Psychometric properties of the Social Phobia and Anxiety Inventory for Children (SPAI-C): A sample of Italian school-aged children from the general population. European Journal of Psychological Assessment, 28, 51-59. http://dx.doi.org/10.1027/1015-5759/a000090

Rapee, R. M., \& Heimberg, R. G. (1997). A cognitive-behavioral model of anxiety in social phobia. Behaviour Research and Therapy, 35, 741-756. http://dx.doi.org 10.1016/S0005-7967(97)00022-3

Reardon, L. E., Leen-Feldner, E. W., \& Hayward, C. (2009). A critical review of the empirical literature on the relation between anxiety and puberty. Clinical Psychology Review, 29, 1-23. http://dx.doi.org/10.1016/j.cpr.2008.09.005

Schmitz, J., Krämer, M., Tuschen-Caffier, B., Heinrichs, N., \& Blechert, J. (2011) Restricted autonomic flexibility in children with social phobia. Journal of Child Psychology and Psychiatry, 52, 1203-1211. http://dx.doi.org/10.1111/j.14697610.2011.02417.x

Schmitz, J., Tuschen-Caffier, B., Wilhelm, F. H., \& Blechert, J. (2013). Taking a closer look: Autonomic dysregulation in socially anxious children. European Child and Adolescent Psychiatry, 22, 631-640. http://dx.doi.org/10.1007/s00787-0130405-y

Siess, J., Blechert, J., \& Schmitz, J. (2014). Psychophysiological arousal and biased perception of bodily anxiety symptoms in socially anxious children and adolescents: A systematic review. European Child and Adolescent Psychiatry, 23, 127-142. http://dx.doi.org/10.1007/s00787-013-0443-5

Spear, L. P. (2009). Heightened stress responsivity and emotional reactivity during pubertal maturation: Implications for psychopathology. Development and Psychopathology, 21, 87-97. http://dx.doi.org/10.1017/s0954579409000066

Steinberg, L. (2005). Cognitive and affective development in adolescence. Trends in Cognitive Sciences, 9, 69-74. http://dx.doi.org/10.1016/j.tics.2004.12.005

Van West, D., Claes, S., Sulon, J., \& Deboutte, D. (2008). Hypothalamic-pituitary-adrenal reactivity in prepubertal children with social phobia. Journal of Affective Disorders, 111, 281-290. http://dx.doi.org/10.1016/j. jad.2008.03.006

Van den Bos, E., De Rooij, M., Miers, A. C., Bokhorst, C. L., \& Westenberg, P. M. (2014). Adolescents' increasing stress response to social evaluation: Pubertal effects on cortisol and alpha-amylase during public speaking. Child Development, 85, 220-236. http://dx.doi.org/10.1111/cdev.12118

Weems, C. F., \& Costa, N. M. (2005). Developmental differences in the expression of childhood anxiety symptoms and fears. Journal of the American Academy of Child and Adolescent Psychiatry, 44, 656-663. http://dx.doi.org/10.1097/01.chi 0000162583.25829.4b

Weems, C. F. (2008). Developmental trajectories of childhood anxiety: Identifying continuity and change in anxious emotion. Developmental Review, 28, 488-502. http://dx.doi.org/10.1016/j.dr.2008.01.001 
Westenberg, P. M., Drewes, M. J., Goedhart, A. W., Siebelink, B. M., \& Treffers, P. D. A. (2004). A developmental analysis of self-reported fears in late childhood through mid-adolescence: Social-evaluative fears on the rise? Journal of Child Psychology and Psychiatry, 45, 481-495. http://dx.doi.org/10.1111/j.1469-7610. 2004.00239.x
Westenberg, P. M., Bokhorst, C. L., Miers, A. C., Sumter, S. R., Kallen, V. L., Van Pelt, J. \& Blöte, A. W. (2009). A prepared speech in front of a pre-recorded audience: Subjective, physiological, and neuroendocrine responses to the Leiden Public Speaking Task. Biological Psychology, 82, 116-124. http://dx.doi.org/10.1016/j. biopsycho.2009.06.005 